\title{
Candidate antiviral drugs for COVID-19 and their environmental implications: a comprehensive analysis
}

\author{
Partha Biswas ${ }^{1} \cdot$ Mohammad Mehedi Hasan ${ }^{2} \cdot$ Dipta Dey $^{3} \cdot$ Ana Carla dos Santos Costa ${ }^{4} \cdot$ Shakil Ahmed Polash $^{5}$. \\ Shabana Bibi ${ }^{6}$. Nadim Ferdous ${ }^{7}$. Md. Abu Kaium ${ }^{1}$. MD. Hasanur Rahman ${ }^{8}$. Fardin Kamal Jeet ${ }^{9}$. \\ Stavros Papadakos ${ }^{10} \cdot$ Khairul Islam $^{2} \cdot$ Md. Sahab Uddin ${ }^{11,12}$
}

Received: 9 April 2021 / Accepted: 18 August 2021 / Published online: 12 September 2021

(C) The Author(s), under exclusive licence to Springer-Verlag GmbH Germany, part of Springer Nature 2021

\begin{abstract}
Emerging from Wuhan, China, SARS-CoV-2 is the new global threat that killed millions of people, and many are still suffering. This pandemic has not only affected people but also caused economic crisis throughout the world. Researchers have shown good progress in revealing the molecular insights of SARS-CoV-2 pathogenesis and developing vaccines, but effective treatment against SARS-CoV-2-infected patients are yet to be found. Several vaccines are available and used in many countries, while many others are still in clinical or preclinical studies. However, this involves a long-term process, considering the safety procedures and requirements and their long-term protection capacity and in different age groups are still questionable. Therefore, at present, the drug repurposing of the existing therapeutics previously designed against other viral diseases seems to be the only practical approach to mitigate the current situation. The safety of most of these therapeutic agents has already been tested. Recent clinical reports revealed promising therapeutic efficiency of several drugs such as remdesivir, tenofovir disoproxil fumarate, azithromycin, lopinavir/ritonavir, chloroquine, baricitinib, and cepharanthine. Besides, plasma therapies were used to treat patients and prevent fatal outcomes. Thus, in this article, we have summarized the epidemiological and clinical data from several clinical trials conducted since the beginning of the pandemic, emphasizing the efficiency of the known agents against SARS-CoV-2 and their harmful side effects on the human body as well as their environmental implications. This review shows a clear overview of the current pharmaceutical perspective on COVID-19 treatment.
\end{abstract}

Keywords COVID-19 · SARS-CoV-2 $\cdot$ Antiviral drugs $\cdot$ Candidate drugs $\cdot$ Environmental implications $\cdot$ Side effects

Responsible Editor: Lotfi Aleya

Md. Sahab Uddin

msu-neuropharma@hotmail.com; msu_neuropharma@hotmail.com

1 Department of Genetic Engineering and Biotechnology, Faculty of Biological Science and Technology, Jashore University of Science and Technology, Jashore 7408, Bangladesh

2 Department of Biochemistry and Molecular Biology, Faculty of Life Science, Mawlana Bhashani Science and Technology University, Tangail 1902, Bangladesh

3 Department of Biochemistry and Molecular Biology, Faculty of Life Science, Bangabandhu Sheikh Mujibur Rahman Science and Technology University, Gopalganj 8100, Bangladesh

4 Federal University of Bahia, Salvador, Bahia, Brazil

5 School of Science, RMIT University, Melbourne, Victoria 3001, Australia
6 Yunnan Herbal Laboratory, School of Ecology and Environmental Sciences, Yunnan University, Kunming 650091, Yunnan, China

7 Department of Biotechnology and Genetic Engineering, Faculty of Life Science, Mawlana Bhashani Science and Technology University, Tangail 1902, Bangladesh

8 Department of Biotechnology and Genetic Engineering, Faculty of Life Science, Bangabandhu Sheikh Mujibur Rahman Science and Technology University, Gopalganj 8100, Bangladesh

9 Biotechnology and Genetic Engineering Discipline, Khulna University, Khulna, Bangladesh

10 First Department of Pathology, School of Medicine, National and Kapodistrian University of Athens (NKUA), Athens, Greece

11 Department of Pharmacy, Southeast University, Dhaka, Bangladesh

12 Pharmakon Neuroscience Research Network, Dhaka, Bangladesh 


\section{Introduction}

The recent outbreak of COVID-19 caused by severe acute respiratory syndrome coronavirus-2 (SARS-CoV-2) has spread from Wuhan province in China to other countries. On March 11, 2020, the WHO (World Health Organization) declared the SARS-CoV-2 pandemic (WHO 2020). By March 26, 2021, there were 126,417,043 cases and 2,771,626 deaths reported (Kolluri and Murthy 2021). Figure 1 shows the severity of this infection around the globe. The information is retrieved from the coronavirus online portal. Many cities were being placed in lockdown, and strict restrictions were imposed on human interactions soon after the pandemic declaration. The restrictions on travel and businesses significantly impacted the economic condition, resulting in the financial index's decline. The epidemiology and the transmission of virus patterns were confoundedly crucial for understanding these difficulties; the infections and mortality rate was increased daily. The WHO called the infection induced by this new coronavirus strain as COVID-19 (corona virus disease 2019) (Zed 2020; Ashour et al. 2020). The signs of COVID-19 are similar to those of a respiratory infection or pneumonia. The gradual respiratory failure observed leads to injuries, with the number of cells in monocytes, lymphocytes, leukocytes, cytokines, $\mathrm{T}$ cells, and biomarker-related infections changing in the serious cases (Wang et al. 2020c). These infection strategies of COVID19 are depended explicitly on their strains and genomic pattern (Torres et al. 2021; Hasana et al. 2021). However, it was quickly shown that COVID-19 also targets other organic systems, whether through overt viral infection or indirect immune response results. Various studies have identified that signs of the virus have been found in the body in many organs, including the pharynx, trachea, lungs, blood, heart, vessels, intestines, male brain, and kidneys. The virus has also been found in a number of body fluids, including mucus, saliva, urine, semen, feces, cerebrospinal fluid, and breast milk
(Nakagawa et al. 2016; Chen et al. 2020). Many research studies have shown that the coronavirus's genome is similar to that of SARS-CoV, responsible for the epidemic in 2002 2003 (Zhou et al. 2020b). Coronavirus is a positive-stranded RNA virus that contains an envelope. It is a virus of the genus beta coronavirus that can affect humans, birds, and other mammals (Bai et al. 2020; Zhu et al. 2020). Four types of coronavirus, such as Hku1, NL63, 229E, and OC43, are responsible for triggering common cold manifestations among the six species (Bai et al. 2020). The viral genomic makeup, evolution, transcription mapping, and virus-human protein interaction were collected a few months after the outbreak.

The data was required to identify therapeutic drugs, vaccine development, patient care, and preventive informational policies. Many treatment strategies have been adopted to prevent the outspread of SARS-CoV-2, with social isolation being the most efficient among them (Cascella et al. 2020). The most widely used testing system against COVID-19 is carried out by detecting the virus's nucleic acid and antibody (IgM, $\mathrm{IgG}$ ) determination in the patient's serum (Esbin et al. 2020). Drug treatments like lopinavir/ritonavir, ribavirin, chloroquine, umifenovir, alpha interferon, and plasma therapy could be applied, but they have many side effects (Million et al. 2020). Various multinational vaccine developers (like Pfizer, Janssen, GlaxoSmithKline, Sinopharm, Sinovac, IMBCAMS, NOVAVAX, Zhifei Longcom, Vector State Research Centre of Virology and Biotechnology, CanSinoBIO, Gamaleya Research Institute of Epidemiology and Microbiology, Moderna, Serum Institute of India, and Sanofi, SK BIO) are engaged in COVID-19 vaccine development, 11 vaccines have been approved, and six have been authorized for emergency use around the world, including Pfizer/BioNTech vaccine; Moderna vaccine; the Russian Sputnik V vaccine; AstraZeneca vaccine in partnership with the University of Oxford; and Sinovac Biotech vaccine.

In this review, we aim to scrutinize the mechanism of action of some selected antiviral drugs that could be used for
Fig. 1 Current statistics of COVID-19 incidence around the globe until March 26, 2021

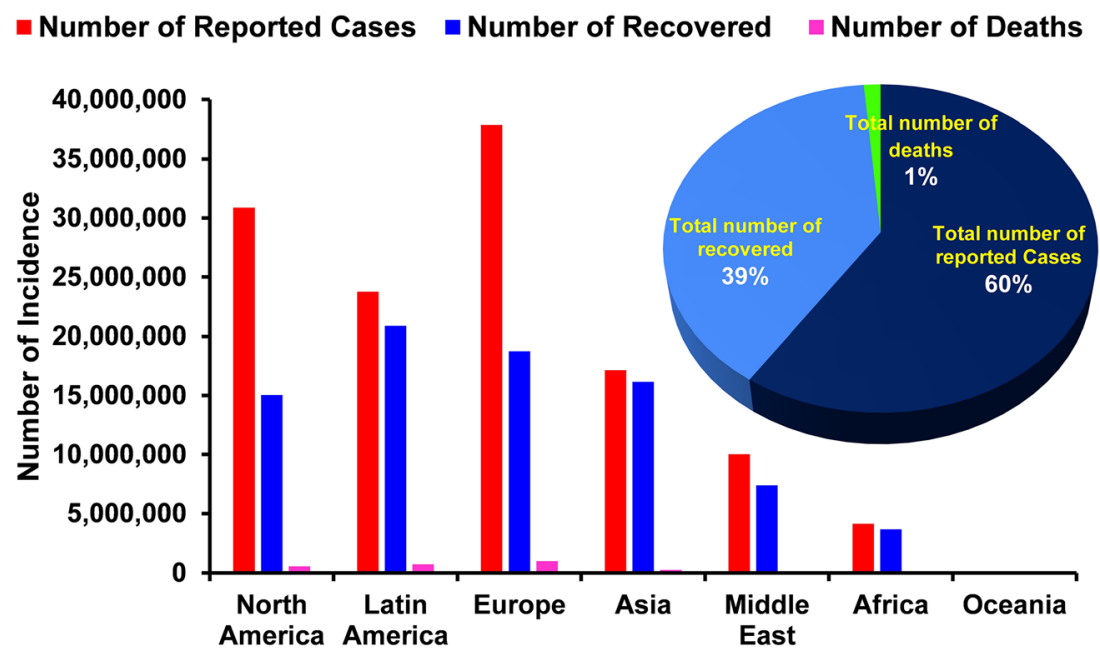


COVID-19 treatment and many other possible outbreaks in the future, and the adverse side effects on the human bodye, as well as environmental implications of these drugs.

\section{Structure, genomic properties, and morphology of SARS-CoV-2}

SARS-CoV-2 has a particular viral protein on its surface, commonly known as spike glycoprotein (S), which mimics a crown-like structure and hence named coronavirus, belonging to the Coronaviridae family (Pillay 2020; Yan et al. 2020). Coronavirus is a positive-sense single-stranded RNA virus of 26 to $32 \mathrm{~kb}$ with 29,891 nucleotides encoded for 9860 amino acids (Wang et al. 2020b). It was discovered that the virus belongs to the Betacoronaviruses ( $\beta-\mathrm{CoV}$ ) (Pillay 2020). The SARS-CoV-2 genome has approximately $80 \%$ match to the SARS-CoV genome and about more than $90 \%$ similarity to the RaTG13 (bat coronavirus) (Pillay 2020; Yan et al. 2020). Its genome was annotated to have 14 ORFs that encode 27 proteins (Huang et al. 2020a). Morphologically, the virus has four fundamental proteins represented by the $\mathrm{S}$ (spike), M (membrane), E (envelope), and N (nucleocapsid) proteins (Mousavizadeh and Ghasemi 2020; van der Hoek et al. 2004). The $\mathrm{S}$ protein, which is $\sim 150 \mathrm{kDa}$, is the major. It uses an $\mathrm{N}$-terminal flag arrangement to collect the viral genome and transport it to the endoplasmic reticulum and is intensely glycosylated at N-terminal (Malik 2020). It contains two functional subunits: one is the S1 subunit (binds to the host cell receptor) towards the N-terminal, and another one is the S2 subunit (directly confers the fusion of the viral and cellular membrane) residing at the C-terminal (Walls et al. 2020; Zhou et al. 2020a; Yuan et al. 2020). The membrane protein is the superabundant viral protein (Malik 2020).

Later studies proposed that the $\mathrm{M}$ protein has a dimeric configuration within the virion. It can portray different conformational changes permitting the binding to the nucleocapsid. On the other hand, the E protein is present in small proportions in the viral proteome (Malik 2020; Pillay 2020). Subsequent studies have proposed that the $\mathrm{M}$ protein and the virion are dimers and the $M$ protein portrays two diverse conformations that allow the binding to the nucleocapsid. On the other hand, protein E, which is $\sim 8-12$ $\mathrm{kDa}$, is less in the virion. The $\mathrm{N}$-terminal and $\mathrm{C}$ terminal domain of nucleocapsid protein are responsible for packaging the viral RNA utilizing diverse mechanisms (Blaising et al. 2013). $\mathrm{N}$ protein also ties nsp3, a vital element of the replicase complex (Blaising et al. 2013). The HE (hemagglutinin-esterase) is another essential protein in a group of $\beta$-coronaviruses (Fehr and Perlman 2015).

\section{Pathogenesis}

HACE2 (human angiotensin-converting enzyme 2) is the key receptor for cellular entry (Jin et al. 2020). Here, hACE2 provides a direct binding site for the superior surface glycoprotein called spike $(\mathrm{S})$ proteins of $\mathrm{nCoV}$ 19. The S protein's receptor-binding domain has a higher affinity than the other SARS-CoV, and infection severity is more critical ( $\mathrm{Hu}$ et al. 2020). In addition, the COVID-19 infection manifests in the cytokine storm induced by the activation of vast amounts of leukocytes such as T cells, B cells, NK (natural killer) cells, dendritic cells, macrophages, neutrophils, monocytes, and resident tissue cells (epithelial and endothelial cells), which secrete vast amounts of proinflammatory cytokines (Azkur et al. 2020). Recently, a study reported that high amounts of cytokines and chemokines were included during the infection time. The cytokines are IL 10, IL9, IL 8, IL 7, IL 1- $\beta$, IP 10, IFN $\gamma, \operatorname{TNF} \alpha$, MIP1 $\alpha$, FGF2, VEGFA, PDGFB, GCSF, GMCSF, etc. (Rothan and Byrareddy 2020). Consequently, some severe cases found high amounts of proinflammatory cytokines, including the following IL2, IL10, IL7, MCP1, TNF $\alpha$, GCSF, IP10, and MIP1 $\alpha$ are critical for escalating disease complications (Asrani and Hassan 2020). Figure 2 depicts the viral pathogenesis of common RNA viruses.

\section{Symptoms}

The primary and most common manifestation of the disease consists of the following symptoms fever, dry cough, severe pneumonia, anemia, dyspnea, myalgia, fatigue, lymphopenia and difficulty in breathing, normal or decreased leukocyte counts, in addition to the less common symptoms that include headache, diarrhea, aches and pains, and loss of taste or smell (Khalaf et al. 2020). Depending on the viremia load, the lungs, cardiovascular tissue, kidneys, upper respiratory, and gastrointestinal tract can be affected, worsening the clinical picture of the disease (Robba et al. 2020).

\section{Antiviral therapeutics against COVID-19}

While several COVID-19 vaccines are available, their reliability among different age groups and their longterm protection capacity is still questionable. Therefore, it is necessary to develop antiviral drugs against SARSCoV-2. However, until now, no antivirals have been thoroughly proven effective. The antiviral acts by various mechanisms such as blocking the viral particle's 
Fig. 2 Pathogenesis of human infection causing common RNA viruses. $\mathrm{HCV}$, hepatitis $\mathrm{C}$ virus; VSV, vesicular stomatitis virus; CHIKV, chikungunya virus.

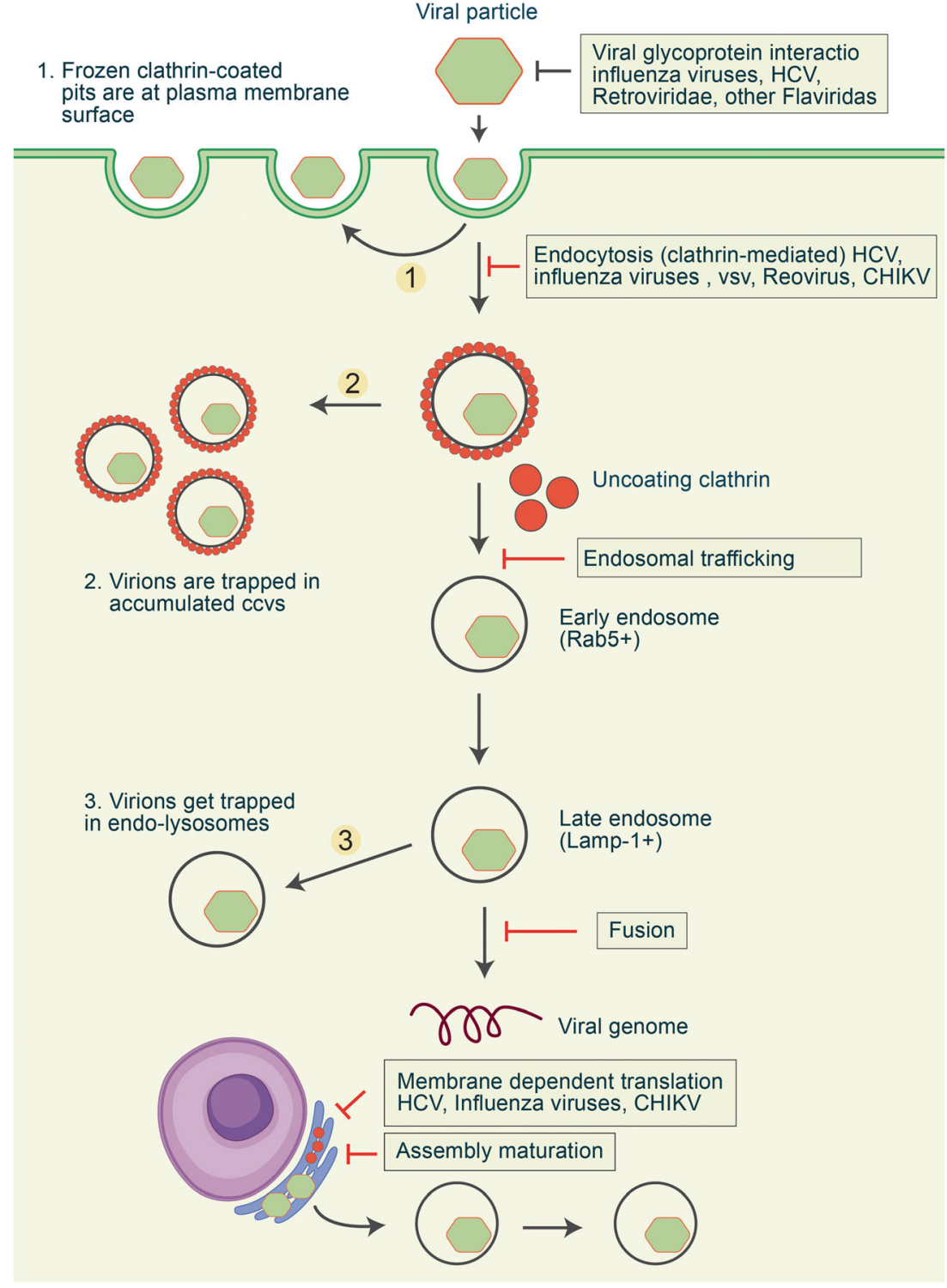

entry, preventing virus-encoded enzymes, attacking a specific host needed to block the formation of viral particle, or replicating the virus (Kumar et al. 2020; Zumla et al. 2016). The following antiviral drugs' list works by disrupting the entry, inhibiting the protease, and several other methods in the table below (Table 1). Some antiviral drugs have shown positive results in treating patients and reducing the risk of disease and unfavorable clinical outcomes. Antiviral drugs are aimed at curing the disease caused by a viral infection. Further research and studies are needed to make the drugs listed against COVID-19 or other viruses receive positive and progressive results. These drugs can be used effectively as therapeutic agents against similar viruses in future cases. Figure 3 depicts chemical structures of the selected candidate antiviral drugs.

\section{Mechanism of action of the candidate antiviral drugs against SARS-CoV-2}

\section{SARS-CoV-2 entry inhibitors}

\section{Remdesivir}

Remdesivir (RDV, Fig. 3) is an antiviral drug with broadspectrum potential that works against the RNA virus. The drug was initially created to be used to treat Ebola disease (Gordon et al. 2020). Many research studies have recently demonstrated that this antiviral drug has shown significant efficiency against SARS-COV-2 and SARS-COV (Ko et al. 2020; Al-Tawfiq et al. 2020). Moreover, they have revealed that remdesivir (RDV) exerts its antiviral activity by inhibiting the RNA transcription by blocking the function of RdRp, 
Table 1 Mechanism of action and side effects of candidate drugs for COVID-19 treatment.

\begin{tabular}{|c|c|c|c|c|}
\hline Drugs name & $\begin{array}{l}\text { Mechanism of action against } \\
\text { SARS-CoV-2 }\end{array}$ & Drug target & Side effects & References \\
\hline \multicolumn{5}{|c|}{ SARS-CoV-2 entry inhibitors } \\
\hline $\begin{array}{l}\text { Remdesivir } \\
\text { (RDV) }\end{array}$ & $\begin{array}{l}\text { Inhibition of viral RNA transcription by } \\
\text { blocking the function of the } \\
\text { RNA-dependent RNA polymerase en- } \\
\text { zyme (RdRp) }\end{array}$ & Viral & $\begin{array}{l}\text { RNA-dependent RNA polymerase } \\
(\mathrm{RdRp})\end{array}$ & $\begin{array}{l}\text { Liver damage, } \\
\text { high allergic } \\
\text { reaction, and } \\
\text { low blood } \\
\text { pressure }\end{array}$ \\
\hline
\end{tabular}

(2020a); Food

and

Administration

(2020b)

Tenofovir

disoproxil

fumarate (TDF)

Suppression of viral reverse transcriptase enzyme activity

Azithromycin

Suppresses the viral replication process by

detaching the viral genetic materials from the lysosomes by increasing $\mathrm{pH}$ levels. It also shows effective antiviral activity in combination with hydroxychloroquine (HCQ) or chloroquine (CQ)

\section{SARS-CoV-2 protease inhibitors}

Suppress the activity of 3CLpro and Viral protease Lopinavir/riton- interrupt with the replication mechanism avir

Chloroquine

Hinders molecular crosstalk governed by SARS-CoV-2 by inhibiting MAP kinase and altering viral assembly, budding, and interfering with the proteolytic processing of protein $\mathrm{M}$

\section{Other mechanisms of action}

Baricitinib

Cepharanthine (CEP)

Favipiravir

Wishart et al.

(2008); Law

et al. (2014)

Galidesivir
Stops downstream signaling molecules and Viral reversible proinflammatory mediators' activation, through inhibiting JAK1/2 activity

Suppresses the activation of nuclear factor kappa $\beta$, nitric oxide and cytokine production. Cyclooxygenase expression inhibits the viral replication

When consecutively added and incorporated, Favipiravir-RTP into the RNA strand completely restricts the elongation or extension by cap-snatching

Ribavirin triphosphate (RTP) directly binds Viral RdRp the nucleotide-binding site of the enzyme that does not allow the correct nucleotide to attach. Thus, inhibits the synthesis of viral RNA

The modified residue of this drug causes Viral RdRp premature interruption of the synthesis of viral RNA (JAK1) and 2 (JAK2)

Viral replication enzyme

Viral RdRp

(RNA

dependent

RNA

polymerase) protein
Viral reverse
transcriptase enzyme

Viral endosomal vesicles and lysosomes

Viral protease Janus kinase 1

(RNA-dependent RNA polymerase) protein
Headache, dysentery, and vomiting of low to medium speed

Sudden cardiac failure, cardiovascular death, heart dysfunction, and inflammation or laryngitis

Gastrointestinal complications, including anorexia, nausea, abdominal pain, or diarrhea

Arrhythmias, heart failure, ventricular hypertrophy, hypokinesia, valvular dysfunction, and pulmonary arterial hypertension

Decreased neutrophils as well as lymphocyte counts

Headaches, dizziness, and stomach ache

Weight loss and increased serum concentration of liver function enzymes, such as aspartate aminotransferase, alkaline phosphatase, and alanine aminotransferase

(RNA-dependent RNA polymerase) protein

Nausea, weight loss or gain, and diarrhea
Ruane et al.

(2013); Del

(2020)

Damle et al. (2020); Lane

et al. 2020;

Lighter and

Zhang et al. (2020)

Wang et al. (2020a); $\mathrm{Hu}$ et al. (2020)

Fleming (2016); Cingolani et al. (2020)

Zhou et al. (2020b); Pillay (2020)

Jin et al. (2013)
Raabe (2020) 
Table 1 (continued)

\begin{tabular}{|c|c|c|c|c|}
\hline Drugs name & $\begin{array}{l}\text { Mechanism of action against } \\
\text { SARS-CoV-2 }\end{array}$ & Drug target & Side effects & References \\
\hline \multicolumn{5}{|l|}{$\begin{array}{l}\text { Taylor et al. } \\
\text { (2016) }\end{array}$} \\
\hline Umifenovir & $\begin{array}{l}\text { In the case of enveloped viruses, it interacts } \\
\text { closely with the lipid envelope of the } \\
\text { virus by intracellular trafficking and } \\
\text { clathrin-mediated exocytosis }\end{array}$ & $\begin{array}{l}\text { Viral spike } \\
\text { glycoprotein }\end{array}$ & $\begin{array}{l}\text { Acute allergic reaction in the human body } \\
\text { with hypersensitivity, nausea/vomiting }\end{array}$ & $\begin{array}{l}\text { Blaising et al. } \\
\text { (2013) }\end{array}$ \\
\hline Nitazoxanide & $\begin{array}{l}\text { Inhibition of viral transcription factor IE2 } \\
\text { (immediate early 2) and hemagglutinin }\end{array}$ & Viral N protein & $\begin{array}{l}\text { Abdominal pain, nausea, diarrhea, } \\
\text { headache, and changes in urine }\end{array}$ & $\begin{array}{l}\text { Shakya et al. } \\
\text { (2018) }\end{array}$ \\
\hline Tocilizumab & $\begin{array}{l}\text { T-cells, fibroblasts, monocytes, } \\
\text { lymphocytes, and B-cells produce IL- } 6 \text {, } \\
\text { which is a proinflammatory cytokine. } \\
\text { IL- } 6 \text { works rapidly and induces the se- } \\
\text { cretion of many substances like serum } \\
\text { amyloid A, haptoglobin, C-reactive } \\
\text { protein, } \alpha \text {-1-antichymotrypsin, and fi- } \\
\text { brinogen }\end{array}$ & IL-6 & $\begin{array}{l}\text { Upper respiratory tract infection, headache, } \\
\text { nasopharyngitis, injection site reaction, } \\
\text { and hypertension }\end{array}$ & $\begin{array}{l}\text { Tanaka et al. } \\
\text { (2014) Guaraldi } \\
\text { et al. (2020) }\end{array}$ \\
\hline Dexamethasone & $\begin{array}{l}\text { Emargination and inhibition of neutrophil } \\
\text { apoptosis and phospholipase A2. This } \\
\text { results in the inhibition of NF-kB and } \\
\text { other inflammatory transcription factors. } \\
\text { Also decreased the production of arachi- } \\
\text { donic acid derivatives. Glucocorticoids } \\
\text { induce the expression of } \\
\text { antiinflammatory genes such as IL-10 }\end{array}$ & $\begin{array}{l}\text { COVID-19 main } \\
\text { protease }\end{array}$ & $\begin{array}{l}\text { Stomach pain or cramp, headaches, } \\
\text { dizziness, insomnia, menstrual cycle } \\
\text { changes, and weight gain, } \\
\text { hyperglycemia, gastrointestinal } \\
\text { hemorrhage, and psychosis }\end{array}$ & $\begin{array}{l}\text { Solinas et al. } \\
\text { (2020); } \\
\text { Group (2020) }\end{array}$ \\
\hline
\end{tabular}

which leads the viral particle to avoid its proofreading mechanism by its exoribonuclease enzymes (Huang et al. 2020b).

Studies have also noted that the RDV shows an effective response against various virus families known as the Filoviridae, Pneumoviridae, Orthocoronavirinae, and the Paramyxoviridae (Tchesnokov et al. 2019a). A research study noted that the RDV could target RdRp of the SARS virus and its nsp14 exoribonuclease by inhibiting its RNA transcription (Agostini et al. 2018). The pharmacokinetics of RDV in the human body has been evaluated through modulating various dose interventions among $3 \mathrm{mg}$ and $225 \mathrm{mg}$, which show no adverse effects or toxicity in the kidney or liver (Cao et al. 2020b). Pharmacokinetics data of RDV have shown that the half-life of RDV is approximately $35 \mathrm{~h}$, including the fact that the dose range of RDV for treating nSARS-COV-2 patients is approximately $200 \mathrm{mg}$ for the first day and $100 \mathrm{mg}$ after 10 days, and these doses are injected intravenously over 30-60 min (Tempestilli et al. 2020). Pre-clinical research studies using an in vivo model of COVID-19 in mice reported that $\mathrm{RDV}$ prohibitively reduces pulmonary uptake of COVID-19. Consequently, there is a reduction in disease progression and improvement in respiratory functions (Pruijssers et al. 2020). Recently, a hospital-based research study has disclosed that a group of scientists used RDV on 53 patients hospitalized with SARS-CoV-2 infection. They reported that among the 53 patients who received the dose of RDV for 10 days, 25 patients were released from the hospital due to recovering from the nSARS-COV-2 viral infection (Pundi et al. 2020). The antiviral strategy adopted by RDV in inhibiting SARSCoV-2-mediated pathogenesis is illustrated in Fig. 4.

In April 2020, the NIAID (National Institute of Allergy and Infectious Diseases) of the USA revealed the preclinical data of RDV on COVID-19-infected patients. They showed that they used RDV in 1,063 COVID-19 patients, and the recovery in these patients was $31 \%$ faster compared to patients treated with placebo (Beigel et al. 2020). On April 29, 2020, the Gilead reported three clinical RDV trials on the hospitalized COVID-19 patients. They revealed the clinical results by regulating two-dose criteria known as the 5-day and 10-day durations to identify the antiviral efficiency of $\mathrm{RDV}$ on the COVID-19-hospitalized patients. They noted that the patients with a 10-day dose duration showed a significant improvement compared to the patients with a 5-day dose duration (Singh et al. 2020). Consequently, on May 1, 2020, the FDA (Food and Drug Administration) of the USA temporarily allowed the health authorities to use the RDV on the patients hospitalized with COVID-19 based on the significant efficiency of RDV's clinical studies (Food and Administration 2020a).

\section{Tenofovir disoproxil fumarate}

Tenofovir disoproxil fumarate (TDF, Fig. 3) is a primary precursor product of tenofovir, a nucleotide analogue that 


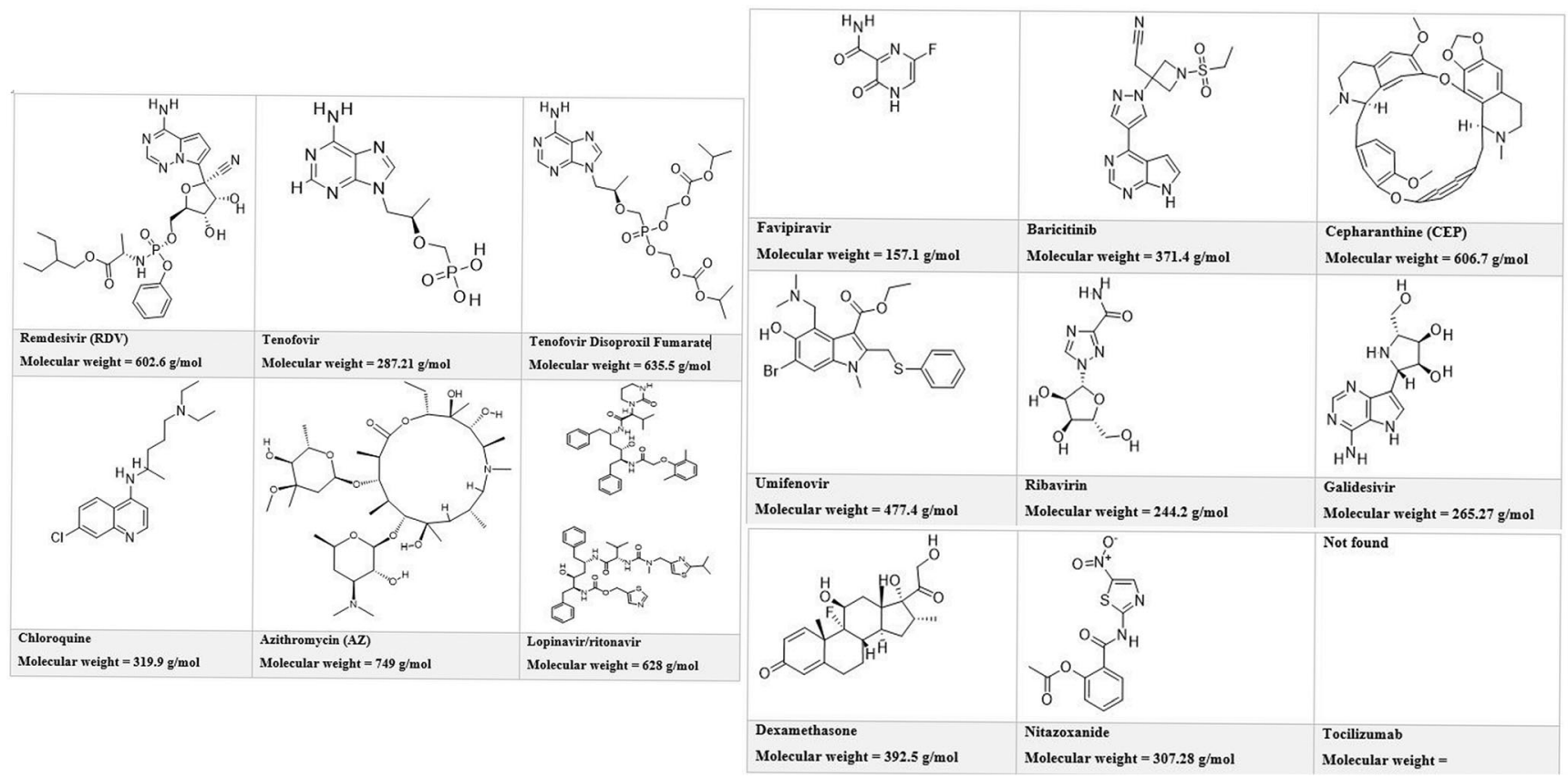

Fig. 3 Chemical structures of selected candidate antiviral drugs for COVID-19 treatment

can exhibit its antiviral role against several types of retroviruses known as hepadnaviruses, HIV-1, and HIV-2 (Gengiah et al. 2012). This nucleotide analogue exhibits its role by possessing an explicit pharmacological activity, low physiological toxicity, and antiviral resistance against viral pathogens (Callebaut et al. 2015). TDF consumption results in an immediate modification into tenofovir-diphosphate that can suppress the activity of reverse transcriptase enzyme of HIV-1 virus and the DNA replication of the body's macrophages; consequently, the several cells do not naturally divide. To block the HIV-1 virus reverse transcriptase enzyme activity, tenofovir-diphosphate mimics deoxyadenosine $5^{\prime}$-triphosphate, accumulating in the DNA fragment of the HIV during the transcription process (Ruane et al. 2013). Consequently, after incorporating itself into the DNA fragment of the HIV, the tenofovir-diphosphate inhibits the HIV reverse virus transcriptase activity and blocks the DNA replication process that is the leading cause for suppressing the DNA development of many viruses (Ray et al. 2016). The TDF half-life of serum and intracellular are respectively $17 \mathrm{~h}$ and $>60 \mathrm{~h}$, which is a longer half-life compared to other rival or similar nucleosides, demonstrating the role of TDF against viral pathogens (Chapman et al. 2003). The pharmacological efficiency of TDF is related to its volume of dose production. The maximum dose of TDF for adults is around $300 \mathrm{mg}$ per day (Gordon et al. 2013). Many clinical research studies of TDF on SARS-CoV-2 patients showed significant results for using it as a therapeutic agent. An experimental research study on SARS-CoV-2 examined the activity of TDF in both vivo and vitro models and observed a beneficial change (Clososki et al. 2020).

\section{Azithromycin with or without other drugs}

Azithromycin (AZ, Fig. 3) is a macrolide-based antibacterial agent with a large spectrum performance and has a big scale of allocation and the expansive activity of half-life time (Lode et al. 1996). This drug is mostly used to treat bacterial infections in the human body's enteric, genitourinary, and respiratory systems (Noedl et al. 2007). There is no significant evidence for AZ's use to treat viral infections, and there is no significant clinical information about AZ's use in the treatment of COVID-19. However, several mechanisms of action have been reported for the alleged antiviral activity exerted by AZ. The AZ is not an acute base, but it can coagulate at the intracellular ventricles of endosomes and lysosomes, which increase the $\mathrm{pH}$ level. This effectively suppresses the viral replication process by detaching the lysosomes' viral genetic materials (Tyteca et al. 2002). Furthermore, a low pH environment is needed to disrupt the coated envelope of viruses like HIV, influenza, and SARS-CoV-2 viruses (Homolak and Kodvanj 2020).

AZ's alleged antiviral activity is regulated by the general increase in the host body's interferon (IFN) to induce antiviral activities (Li et al. 2019). Many studies have suggested that $\mathrm{AZ}$ is responsible for inducing identification receptors, IFNs, and IFN expression genes that cause the suppression of the viral replication process (Menzel et al. 2016). Moreover, AZ plays a crucial role in bronchial epithelial cells by regulating its function and minimizing the mucosal secretion rate to regulate the lung's specific functions (Cramer et al. 2017). Recently, a quantum mechanics research study suggested that for the distinct SARS-CoV-2, AZ is fast enough to play an 
efficient role in inhibiting viral penetration by attaching to the body's ACE2 (angiotensin-converting enzyme-2) receptors (Braz et al. 2020). Hospitals and several scientists have started using AZ in patients with SARS-CoV-2, combining it with other drugs, such as hydroxychloroquine (HCQ) or chloroquine (CQ) (Damle et al. 2020). However, clinical data have reported that $\mathrm{AZ}$ can generate more acute disintegration of the acidic environment than HCQ or CQ (Principi and Esposito 2020). A research study found that HCQ showed antiviral activity against SARS-CoV-2 by reducing viral load, and AZ amplifies HCQ's antiviral activity. The same research group has revealed AZ's clinical data combined with HCQ, concluding that after 7-day dose period, $83 \%$ of patients showed a negative COVID-19 result and 93\% after 8 days (Gautret et al. 2020a).

\section{SARS-CoV-2 protease inhibitors}

\section{Lopinavir/ritonavir}

Lopinavir (Fig. 3) is an antiretroviral human immunodeficiency virus (HIV) protease inhibitor used in combination with other antiretrovirals created in 1998 to prevent HIV resistance against ritonavir, another protease inhibitor (De Clercq 2007). It is used exclusively in combination with ritonavir. The combination is necessary due to the low oral bioavailability and biotransformation of lopinavir (Zhang et al. 2020). Ritonavir is a drug that inhibits the enzymes responsible for the metabolism of lopinavir. Therefore, the administration of both drugs simultaneously increases exposure to lopinavir and enhances antiviral activity. It was demonstrated that it has more advantageous properties in co-administration with low-dose ritonavir and other protease inhibitors that an independent inhibitor. Thus, it is currently most commonly used as a reinforcement of other protease inhibitors. The enzyme 3-chymotrypsin-like protease (3CLpro) of SARS-CoV-2 plays an essential role in processing the viral RNA. As lopinavir and ritonavir both are protease inhibitors, they may inhibit the action of 3CLpro and interrupt the viral replication process' and exit from host cells (Fig. 4) (Anand et al. 2003; Zhang et al. 2020). Several research studies have been conducted to test the efficiency of the lopinavir/ritonavir combination in patients with COVID-19.

Recent research did not show any promising potential for using lopinavir/ritonavir drug combinations against patients with COVID-19. In a trial by Cao et al. (2020a) in Wuhan/ China, which involved 199 adult patients hospitalized with SARS-CoV-2 infection including COVID-19 pneumonia, oral administration of $400 \mathrm{mg}$ lopinavir and $100 \mathrm{mg}$ ritonavir twice a day for 14 days did not reveal any promising results, compared to the other group (100 patients) that received standard care treatment (Cao et al. 2020a). Also, comparing with standard supportive care, lopinavir/ritonavir treatment did not reduce the duration of viral RNA detectability or viral RNA loads. At the end of 28-day trial, the viral RNA was still found in about $40.7 \%$ of the patients in the lopinavir/ritonavir group. Another randomized trial revealed that lopinavir/ritonavir contributes little benefit to improving COVID-19 hospitalized patients' clinical outcome over supportive care ( $\mathrm{Li}$ et al. 2020). This study enrolled a total of $86 \mathrm{mild} /$ moderate COVID-19 patients, of which 34 patients were randomly assigned to receive lopinavir/ritonavir, 35 to umifenovir, and 17 to placebo. It was found that the average time of positiveto-negative conversion of SARS-CoV-2 nucleic acid and conversion rates on the 7 th and 14th day was similar between these groups.

There was no difference between antipyresis, cough alleviation, or chest CT rates improvement on the 7 th and 14 th day. On day 7 th day, eight $(23.5 \%)$ patients in the group that received lopinavir/ritonavir, three $(8.6 \%)$ in the group that received umifenovir, and two $(11.8 \%)$ in the control group had a decline from critical to moderate clinical status. However, it was observed that patients who received lopinavir/ritonavir had more gastrointestinal symptoms, affecting their recovery. Indeed, gastrointestinal complications were more common among patients with COVID-19 in the lopinavir-ritonavir trial group. The clinical trial by 90 reported that about $14 \%$ of the patients treated with lopinavir-ritonavir were not able to complete the 14-day course administrated. The main reasons for this were gastrointestinal side effects, including nausea, acute gastritis, abdominal pain, anorexia, and diarrhea. Moreover, skin eruptions, risks of hepatic damage, pancreatitis, cutaneous eruptions, and QT prolongation were also documented with the drug combination.

\section{Chloroquine}

Chloroquine (Fig. 3) is an amino quinolone derivative that was created to be used to treat malaria in the $1940 \mathrm{~s}$. Chloroquine and its derivative hydroxychloroquine (HCQ) were also used to treat rheumatoid arthritis, HIV, systemic lupus erythematosus, and several other conditions (Plantone and Koudriavtseva 2018). The FDA of the USA revoked the emergency use authorization, which allowed chloroquine and hydroxychloroquine to treat certain hospitalized COVID-19 patients. It has been known from research procedures that the antiviral and antiinflammatory activities of chloroquine might have a significant role in treating patients with COVID-19. Chloroquine showed the potential to stop the viral infection, as it increases the endosomal $\mathrm{pH}$ and interferes with the SARS-CoV cell receptor's glycosylation (Wang et al. 2020a). In addition, chloroquine inhibits the quinone reductase- 2 involved in the biosynthesis of sialic acid, making it a broad antiviral agent.

Furthermore, chloroquine interferes with the SARS-CoV-2 molecular crosstalk by inhibiting MAP kinase and altering virion assembly, budding, and interfering with the proteolytic 
processing of protein $\mathrm{M}$ (Colson et al. 2020; Wang et al. 2020a). Previous researches demonstrated that chloroquine has potent anti-SARS-CoV-I effects in an in vitro model. SARS-CoV-2 also uses the ACE2 surface receptor-like SARS-CoV-I. Researchers suggest that chloroquine may interfere with the ACE2 receptor glycosylation and prevent the attachment of SARS-CoV-2 in the target cells (Lu 2020a; Zhou et al. 2016). The antiviral strategy governed by chloroquine in blocking SARS-CoV-2 pathogenesis is represented in Fig. 4.

The first human trial using chloroquine as a treatment involved more than 100 COVID-19 patients. It showed that chloroquine is superior in reducing the duration of symptoms and exacerbation of pneumonia (Sahraei et al. 2020). Radiological improvement and promotion of negative viral seroconversion were found without any serious negative effects. Due to this early positive result, China incorporated chloroquine in its guidelines as an option to prevent and treat COVID-19 pneumonia. The second human study conducted with HCQ was a nonrandomized trial $(n=36)$. It was found that, compared to control, HCQ with and without azithromycin was significantly more effective in eliminating viral nasopharyngeal transport (as measured by the polymerase chain reaction), showing good results in 3 to 6 days in patients with COVID-19 (Gautret et al. 2020b). In day 6 post-inclusion, virological clearance with HCQ versus control was $70.0 \%$ against $12.5 \%$, respectively $(p=0.001)$. Additionally, virological clearance at day 6 post-inclusion in HCQ with azithromycin, HCQ alone, and control group was $100 \%, 57.1 \%$, and $12.5 \%$ respectively $(p<0.001)$. This study indicates a synergistic effect of azithromycin with HCQ. Although there is not much available evidence until now, due to the COVID-19 pandemic situation, institutions worldwide have already acknowledged the use of chloroquine and HCQ in COVID-19 treatment (Touret and de Lamballerie 2020).

It is important to highlight that chloroquine and hydroxychloroquine can cause arrhythmias, which can be reduced by combining it with other medical products, like azithromycin antibiotic, which has similar heart effects. Other studies 41 have reported severe rhythm complications associated with the use of chloroquine or hydroxychloroquine, especially in high doses or with azithromycin antibiotic. It was also known that cardiac side effects occurred mainly in women. Conduction disorders were the main side effects reported, while the other side effects included heart failure, ventricular hypertrophy, hypokinesia, valvular dysfunction, and pulmonary arterial hypertension.

\section{Other mechanisms of action}

\section{Baricitinib}

Baricitinib (Fig. 3) is a reversible and selective JAK (Janus Kinase) inhibitor important in rheumatoid arthritis pathogenesis (Al-Salama and Scott 2018). JAKs are part of the tyrosine-protein kinase group that plays a crucial function in signaling the proinflammatory pathway, which is overexpressed in rheumatoid arthritis. Baricitinib disrupts the downstream signaling molecules and proinflammatory mediators' activation by blocking JAK $1 / 2$ actions. It is used to treat adults with moderate-to-severe active RA in more than 50 countries across the world (Taylor et al. 2019). Interferon activates transcription through the JAK-STAT signaling pathway (JAK1/2 mediated), leading to the high expression of many genes controlled by interferon that quickly kill cells infected with virus. Most viruses have adopted several approaches to prevent interferons' effects through the blockage of their signaling pathway and viral-encoded factors that provoke the JAK-STAT pathway. Consequently, when the JAKSTAT signal is blocked by baricitinib, an antiviral response mediated by interferon is produced, with a facilitating effect in the COVID-19 evolution (Fleming 2016).

In research by Bronte et al. (2020), 88 patients (44 females/ 44 males) with COVID-19 were under investigation during their hospital stay. The patients received either hydroxychloroquine or antiviral therapy (ritonavir/lopinavir) alone or co-administration (hydroxychloroquine with antiviral therapy). Due to malignancies clinical history, 12 patients (6 females/6 males) were discarded from the study. In the remaining group, 20 patients were included in the treatment regimen with baricitinib, and the rest of the patients were part of the control. They received baricitinib, $4 \mathrm{mg}$ two times daily for 2 days, followed by $4 \mathrm{mg}$ daily for the other days, according to the inclusion criteria and the baricitinib pharmacokinetics. Patients aged above 75 years were given a low dose of $2 \mathrm{mg}$ twice a day for 2 days, accompanied by $2 \mathrm{mg}$ daily. No differences were observed in the COVID-19 symptoms (fever and cough) between the two groups. Patients from the two cohorts had similar clinical respiratory parameters (respiratory frequency, $\mathrm{P} / \mathrm{F}$ ratio, and need for oxygen therapy). However, regarding mortality, patients treated with baricitinib showed a different outcome. Only about $5 \%$ of patients died after the treatment, whereas $45 \%$ of death recorded in the control group $(p<0.001)$.

In a retrospective cohort of 15 patients with moderate/ severe COVID-19, a brief course of baricitinib combined with hydroxychloroquine was used for treatment (Titanji et al. 2020). This was correlated with the clinical outcome's advancement in $73 \%$ of patients and recovery in $80 \%$ of patients (Titanji et al. 2020). Several parameters distinguished this improvement, including decreased inflammation mediators, need for oxygen therapy, body temperature normalization, and recovery.

Baricitinib was found to present several side effects in RA. These include decreased neutrophils and increases in lowdensity and high-density lipoprotein, severe infections, tuberculosis, and some adverse cardiovascular effects (Dougados et al. 


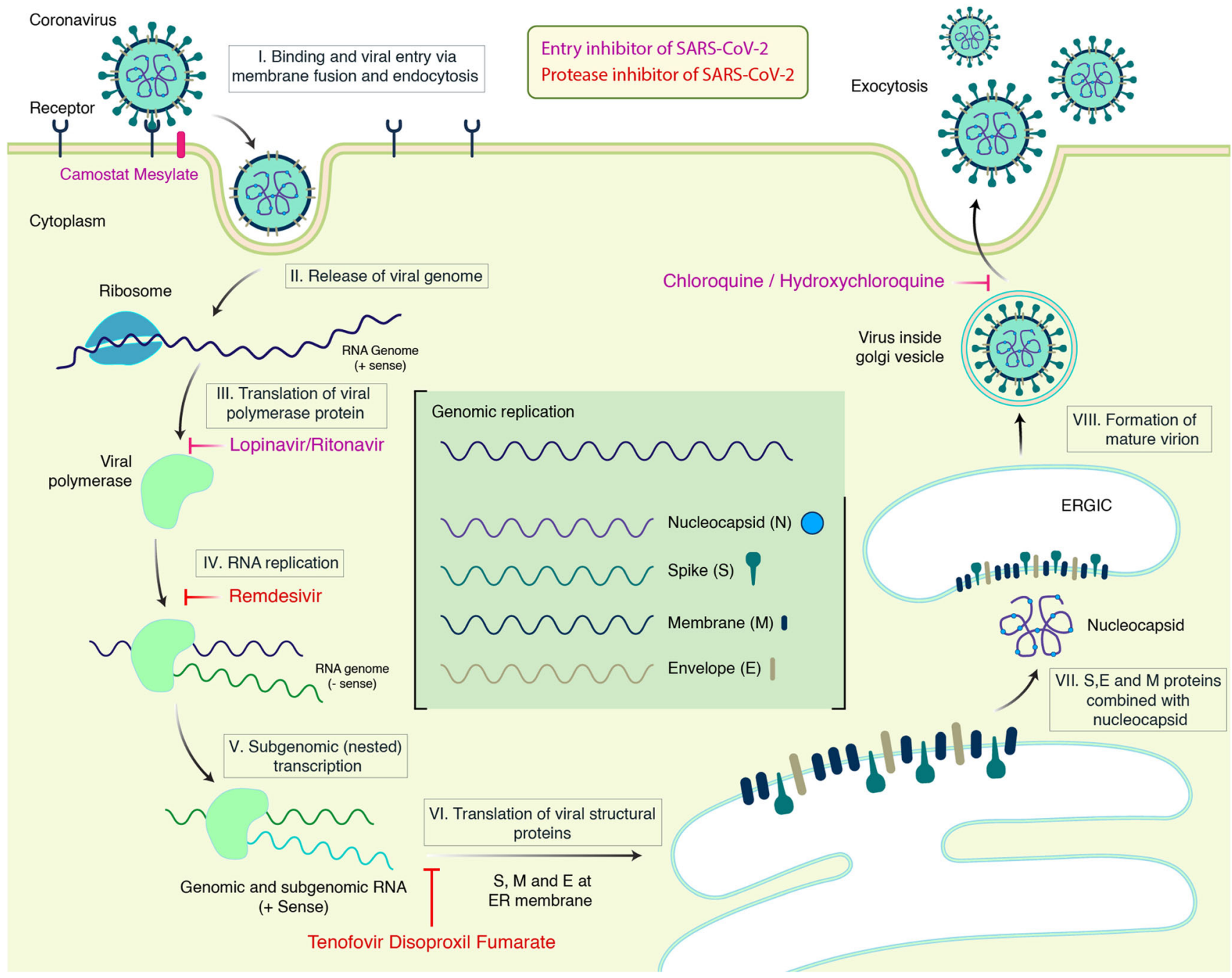

Fig. 4 Treatment strategies of various antiviral drugs against SARS-CoV-2.

2017). However, in COVID-19, baricitinib was well tolerated with no serious side effects (Cingolani et al. 2020) (Cantini et al. 2020). Also, no concomitant infections were observed.

\section{Cepharanthine}

Cepharanthine (CEP, Fig. 3) is a bisbenzylsoquinoline alkaloid that is collected in the tubers of Stephania cepharantha. It can be found in China, Cambodia, Taiwan, Vietnam, and some southeastern Asian countries and is used to treat radiational leukopenia, alopecia, pityodes, middle-ear catarrh viper bite alopecia, and areata since 1951 (Zed 2020) (Rogosnitzky and Danks 2011a). It was used as a conventional remedy for Asia in the last 70-80 years. CEP is a bisbenzylisoquinoline cyclic family member, which also includes naphazoline, tetrandrine, and berberine. It possesses the antiinflammatory, anti-parasitic, anti-oxidative, and antiviral properties that are suggested in the possible use against
COVID-19 (Zed 2020; Ashour et al. 2020; Rogosnitzky and Danks 2011a; Bailly 2019) (Fig. 5).

The antiviral properties of cepharanthine have also been exhibited against HCV-OC43 and SARS-CoV (Zhou et al. 2020b; Kim et al. 2019). Moreover, it was recently demonstrated that, among the screening of 2406 clinically approved drugs, this therapeutic agent works most effectively against SARS-CoV-2 coronavirus (Zhu et al. 2020; Fan et al. 2020). Cepharanthine has gained attention in the treatment of COVID-19 because the genome sequences of SARS-CoV and SARS-CoV-2 are closely related 106 (Ashour et al. 2020; Bailly 2019). Many scientists are conducting studies to identify effective and safe treatment procedures for COVID-19. Recently, many drugs like remdesivir were authorized for COVID treatment by the FDA in the USA but have still lacked information about its use (Wang et al. 2020d; Cascella et al. 2020; Nagatsuka and Nakazawa 1982; Ershun et al. 2014). Besides that, hydroxychloroquine and chloroquine granted by the FDA to treat COVID-19 were finally 
canceled due to the lack of efficiency (Esbin et al. 2020; Fatima et al. 2020). So, it became essential to test the potential role of cepharanthine (CEP) against COVID-19.

Cepharanthine has chemical properties such as solubility, an optical activity that reduces various biological membranes (Bai et al. 2020; Million et al. 2020; Nagatsuka and Nakazawa 1982; Zhang et al. 2005). This drug suppresses the activation of nuclear factor kappa $\beta$, cytokine, and nitric oxide synthesis, as well as cyclooxygenase's expression. There is no precise specification of the doses, but 2-60 mg cepharanthine per day is considered safe and effective for various conditions (Kim et al. 2019; Zhou et al. 2020b). CEP has a half-life of 31.3$36.9 \mathrm{~h}$. After metabolizing in the liver, CEP is disseminated to target tissues. Oshun et al. exhibited that cepharanthine shows antiinflammatory properties by using in the vivo mouse model and examined that CEP reduces the interleukin- $1 \beta$ (IL- $1 \beta$ ), interleukin-6 (IL-6), and tumor necrosis factor $\alpha$ (TNF- $\alpha$ ) in response to natural inflammation (Ershun et al. 2014; Wang et al. 2020b). Another experiment shows that CEP prevents cell death by producing $\mathrm{NO}$ in macrophages (Sakaguchi et al. 2007; Paudel et al. 2016; Yan et al. 2020; Pillay 2020). It has been demonstrated that this therapeutic agent has antiviral potential on HIV (human immunodeficiency virus) by inhibiting the replication of HIV-1 in monocyte and lymphocyte (OKAMOTO et al. 1998; Huang et al. 2020a) and is also used as a preclinical treatment of SARS. Studies were conducted to test the activity of cepharanthine in VeroE6 cells infected by SARS-CoV (Wang et al. 2020d; Nabil et al. 2020). Scientists found four categories of cells in which the first one received CEP treatment, and the second one received CEP treatment post-infection. The third and fourth groups of cells received coadministration of the virus and CEP. The mixture of (cepharanthine and virus) in which the fourth group was incubated at $37^{\circ} \mathrm{C}$ for 2 hours. Using the following techniques, $10 \mu \mathrm{g} / \mathrm{ml}$ concentrations of CEP reduced the cytopathic effect in all groups. The ranges were between 6.0 and 9.5 $\mu \mathrm{g} / \mathrm{ml}$ by $50 \%$ inhibitory concentration (IC50) for the fourth treatment. The data demonstrated amazing results at inhibition, which are similar to the human coronavirus type OC43 (HCV-OC43). This data indicates that cepharanthine has the potential against COVID-19 due to the similarities between SARS-CoV-2, SARS-CoV, and HCoV-OC 43 (Mousavizadeh and Ghasemi 2020; St-Jean et al. 2004).

\section{Favipiravir}

Favipiravir, sometimes regarded as favilavir or fapilavir (Fig. 3), is a pyrazine carboxamide by-product that is processed, by native enzymes, to the ribofuranosyl triphosphate derivative (Cai et al. 2020). It impedes the RdRp proteins required for viral genome replication and transcription. Initially, it was permitted its implication against resistant influenza. However, it is not only effective against Influenza A and $\mathrm{B}$, as it has also shown promising results for treating avian influenza. It has been tested against some of the recent viruses like the Ebola virus, Lassa virus, and now is being evaluated against SARS-CoV-2 (Arab-Zozani et al. 2020).

Favipiravir works as a prodrug and is turned into active favipiravir-RTP intracellularly when it undergoes ribosylation and phosphorylation. It binds to the viral RdRp enzymes, which is essential for mRNA processing and protein preparation. Compared to other influenza antiviral drugs, the mechanism of action for favipiravir is novel. Two hypotheses are prevailing about how favipiravir acts in the organism (Doi et al. 2020). The first study was done by Jin et al. (2013), who constructed panhandle structure RNA in the elongation stage, which indicated favipiravir-RTP's action in the elongation stage. When they incorporated the favipiravir-RTP into the nascent RNA strand, it partially restricted the elongation (single dose). When consecutively added and incorporated, favipiravir-RTP into the RNA strand completely restricts the elongation or extension (Jin et al. 2013). A study has showed that incorporating a favipiravir-RTP molecule inhibits further extension by cap-snatching. It also initiated a reaction related to the influenza virus RNA polymerase transcription by adding 32P-labeled 5'cap1 RNA into the virus-derived 255 RNA complex (Furuta et al. 2013a). In SARS-CoV-2, favipiravir has shown potent antiviral activity, and an experiment on 80 patients showed no serious side effects (Costanzo et al. 2020).

\section{Ribavirin}

Ribavirin (Fig. 3) is an antiviral prodrug with a broadspectrum used against several RNA and DNA viruses. Ribavirin is mainly synthetic guanosine and works against hepatitis C. Ribavirin arrests the viral mRNA synthesis. It is utilized against the HCV strain one and hemorrhagic fever of different types prevailing in the USA. Ribavirin, along with peginterferon alfa $2 \mathrm{a} / 2 \mathrm{~b}$, was considered the standard antiviral treatment before discovering new drugs. Ribavirin is a prodrug that goes through phosphorylation for activation by adenosine kinase. This yields ribavirin mono-, di-, and triphosphate metabolites, which afterwards go through deribosylation and amide hydrolysis (de Souza et al. 2017; Hulseberg et al. 2019). Out of the different mechanisms of action of ribavirin suggested by the studies, there is one that turns into the active form of ribavirin monophosphate (RMP), diphosphate (RDP), and triphosphate (RTP) and directly binds the enzyme nucleotide-binding region that does not let the correct nucleotide to add and thus inhibit viral RNA synthesis. In the dengue virus case, RTP has the inhibitory role in guanylyltransferase and mRNA 2'-O-methyltransferase, resulting in the inhibition of posttranslational capping of the viral mRNA on the $5^{\prime}$ end. Ribavirin binds to the $5^{\prime}$ end in place of guanosine and thus inhibits the 
Fig. 5 The mode of action of cepharanthine (CEP).

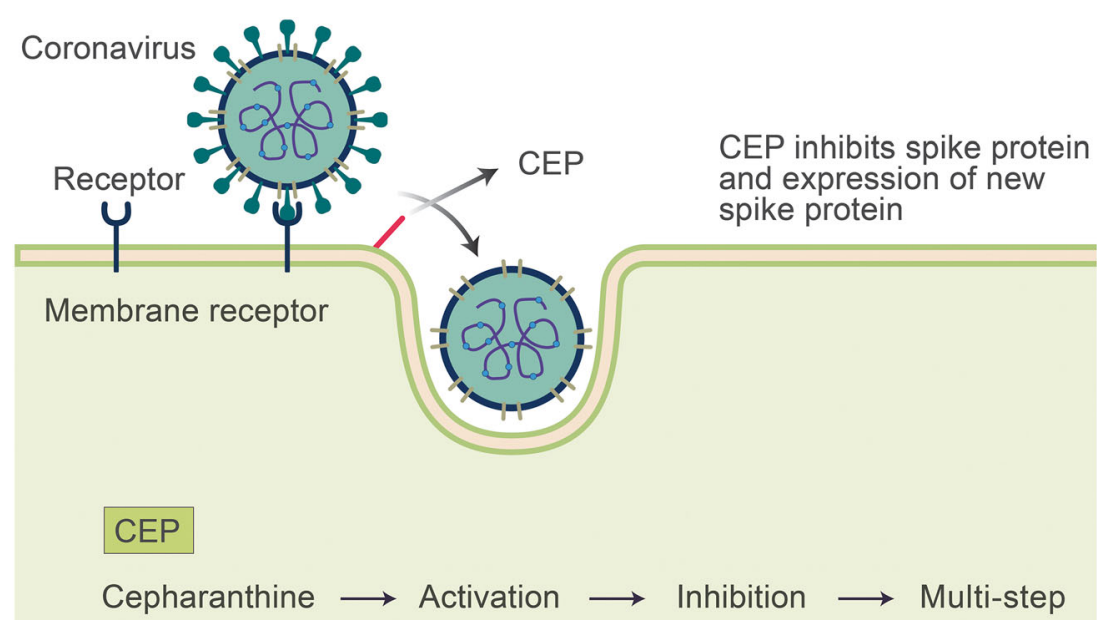

methylation stage (Hulseberg et al. 2019; de Souza et al. 2017).

Inhibition of inosine monophosphate dehydrogenase (IMPDH) is one of ribavirin's major strategies after transforming into ribavirin mono-, di-, and tri-phosphate; the ribavirin monophosphate works as the competitive inhibitor of IMPDH. An essential rate-limiting enzyme is IMPDH for the purine metabolic pathway and works as a catalyst for guanosine synthesis. The triphosphorylated form of guanosine (GTP) is required in viral RNA replication and lymphocyte proliferation. As ribavirin monophosphate inhibits IMPDH, it leads to the depletion of the GTP pool intracellularly. This leads to RNA synthesis inhibition, resulting in suppressed viral RNA replication and immunosuppression (Hofmann et al. 2008) (Fig. 6).

\section{Galidesivir}

Galidesivir (Fig. 3) is relatively a new drug, an adenosine analogue still under human trials. It has been tested against Zaire ebolavirus (Tchesnokov et al. 2019b). It was successful in increasing the survival rates when tested on animal models. It was used in animal models against Zika, Marburg, Ebola, and yellow fever viruses (Babu et al. 2000). In vitro studies provided the following results: it delivered outcomes against positive and negative-sense RNA viruses like arenaviruses and coronaviruses. A clinical study in phase 1 is underway to check this drug's safety in the human body (Westover et al. 2018). The cellular kinase phosphorylates galidesivir into a triphosphate. This modified triphosphate is mistakenly regarded as natural triphosphate by the virus's RNA polymerase. Thus, the modified residue of the drug is taken into RNA synthesis, but not more than one triphosphate, which can be added. This modified structure leads to premature termination of the RNA processing (Taylor et al. 2016).

\section{Umifenovir}

Umifenovir (Arbidol, Fig. 3) is a direct antiviral or hosttargeting, indole-based, dual-acting agent used for influenza and other respiratory infections. China has used this drug since 2006, and Russia had been using this for approximately 25 years. The drug was invented by Russian scientists from different institutes around 40-50 years ago as a collaborative project. The chemical synthesis of the drug started in 1993, as the reports suggest (Blaising et al. 2014). Umifenovir has multiple pathways that work against viruses, and thus, several studies have been conducted to check the efficiency against non-enveloped and enveloped DNA and RNA viruses. These studies include hepatitis B and C viruses, chikungunya virus, Zika virus, herpes simplex, Lassa virus, foot-and-mouth disease, Hantaan virus, Flavivirus, Ebola virus, reovirus, and coxsackievirus B5 (Blaising et al. 2014; Li et al. 2018; Fink et al. 2018; Haviernik et al. 2018). The therapeutic potential of this drug is now being evaluated in COVID treatment. A combination of umifenovir and currently available HIV therapeutics and investigational HIV therapeutics is being used ( $\mathrm{Lu}$ 2020b; Wang et al. 2020f). Umifenovir works based on multiple pathways to exhibit antiviral activity. It is also a host targeting agent as it influences one or more steps of the viral life cycle. Due to this different working pathway, its broadspectrum antiviral activity is seen (Blaising et al. 2014). It can establish non-bonding interactions with aromatic amino acid residues, including tryptophan and tyrosine, being a hydrophobic agent. This enables umifenovir to act directly on the virus. The antiviral activity can also occur due to intracellular trafficking and exocytosis mediated by clathrin (Blaising et al. 2013). In the case of enveloped viruses, it might also directly interact with the lipid envelope (Blaising et al. 2014; Teissier et al. 2011). It could also be stabilized by contact with the plasma membrane and avoid the viral route of entry. As seen 
in influenza, stabilizing the hemagglutinin affects the fusion step and viral entry (Blaising et al. 2014).

As umifenovir interacts with both the viral protein and lipid, the viral replication cycle's downstream process might be affected. The Flaviviridae family of the virus replicates in a membranous-web sub-cellular compartment that requires interaction between protein and lipid, which can easily be affected by umifenovir (Blaising et al. 2014).

\section{Nitazoxanide}

Nitazoxanide (Fig. 3) is a thiazole, a class of broad-spectrum drugs with antiviral and anti-parasitic activity. A vast range of intracellular and extracellular pathogens such as protozoa, helminths, microaerophilic and aerobic bacterial growth, survival, and proliferation are affected by it. Nitazoxanide is the standard treatment for Giardia lamblia and Cryptosporidium parvum infections in healthy (non-immunosuppressed) children and adults. This drug can also be applied to other protozoa, and helminth caused diseases (Shakya et al. 2018). In anaerobic microbes, the drug disrupts the energy metabolism by inhibiting the ferredoxin, flavodoxin oxidoreductase, or pyruvate cycle (Broekhuysen et al. 2000). Nitazoxanide causes damage to the cell membrane of parasitic protozoa. Depolarizing mitochondrial membrane and inhibiting nitroreductase-1, quinone oxidoreductase NQO1, and disulfide isomerase enzymes is the process of killing the protozoa. Additionally, this therapeutic agent can inhibit the detoxifying enzyme glutathione-S-transferase. Thus, modulating the Avr14 gene encodes the alpha-type subunit of glutamate-gated chloride ion channel presented in nematodes. While these different modes of action are observed in protozoa and nematodes, it has a different pathway for viruses. Maturation inhibition of viral transcription factor IE2 (immediate early 2) and hemagglutinin is observed in nitazoxanide. The drug also activates the intracellular protein eukaryotic translation initiation factor $2 \alpha$ (Shakya et al. 2018).

\section{Tocilizumab}

Tocilizumab (Actemra, Fig. 3) is a monoclonal antibody used to inhibit the IL-6 receptor in humans and is mainly used for treating inflammation and autoimmune conditions. This IgG1 class of antibody works on the membrane-bound and soluble receptor of IL-6 (Guaraldi et al. 2020). B-cells, fibroblasts, monocytes, T-cells, and lymphocytes produce IL-6, which is a proinflammatory cytokine. IL-6 works rapidly and induces the secretion of many substances like serum haptoglobin, amyloid A, fibrinogen, C-reactive protein, and $\alpha-1$ antichymotrypsin. It simultaneously inhibits transferrin, albumin, and fibronectin production. These IL- 6 promote cytotoxic T-cell differentiation and antibody production and inhibit regulatory T-cell differentiation (Tanaka et al. 2014) (Fig. 7).

\section{Dexamethasone}

Dexamethasone (Fig. 3) is a synthetic corticosteroid which is also known as MK-125. It is fluorinated at position nine and used for endocrine, dermatologic, collagen, rheumatic, gastrointestinal, respiratory, neoplastic, and many other conditions (Group 2020). Developed in 1957, this drug got FDA approval in 1958, although the oral tablets are discontinued now. Dexamethasone was selected for the randomized evaluation for COVID-19 therapy on patients with severe respiratory complications, which minimized one-third of the mortality rate among patients requiring ventilation and one-fifth among patients requiring oxygen (Johnson and Vinetz 2020). The short-term effect of corticosteroids like dexamethasone has decreased vasodilation, decreased permeability of capillaries, reduced leukocyte migration to inflammation sites, and binds glucocorticoid. It mediates a change in gene expression
Fig. 6 The mechanism of action of ribavirin. IMPDH, inosine-5'monophosphate dehydrogenase; RMP, ribavirin monophosphate; GDP, guanosine diphosphate; GTP, guanosine triphosphate; dGDP, deoxyguanosine diphosphate; dGTP, deoxyguanosine triphosphate.

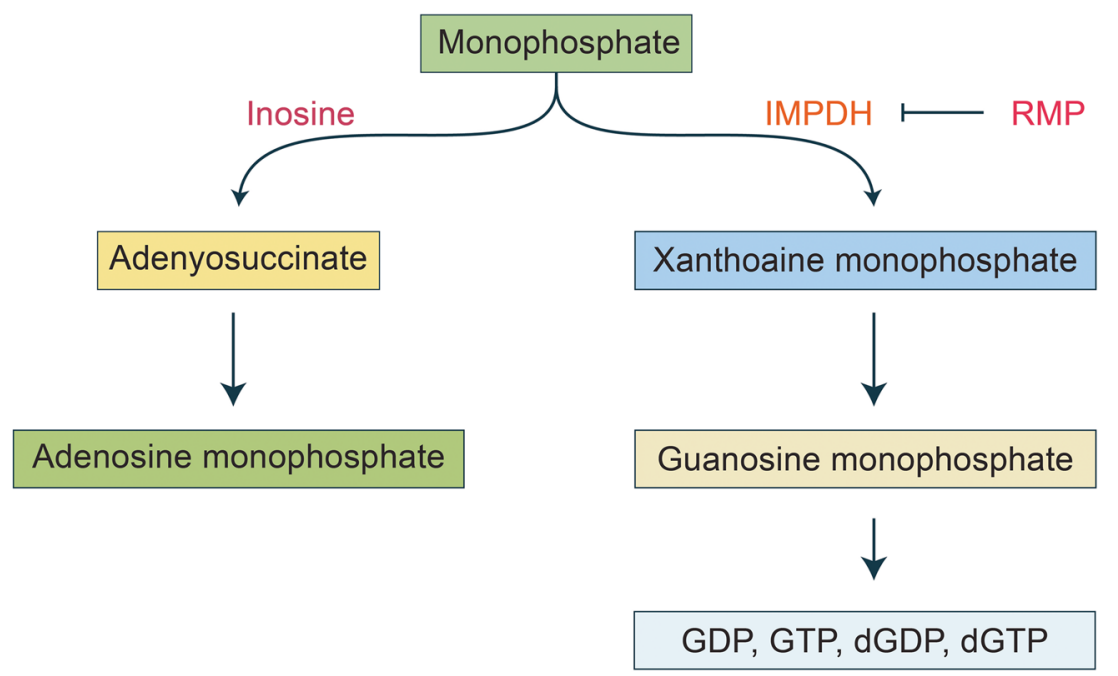


Fig. 7 The mechanism of action of tocilizumab. LPS, lipopolysaccharide; MD-2, myeloid differentiation factor 2 ; TLR4, Toll-like receptor 4; MyD88, myeloid differentiation primary response 88 ; NF-kB, nuclear factor kappa light chain enhancer of activated B cells.

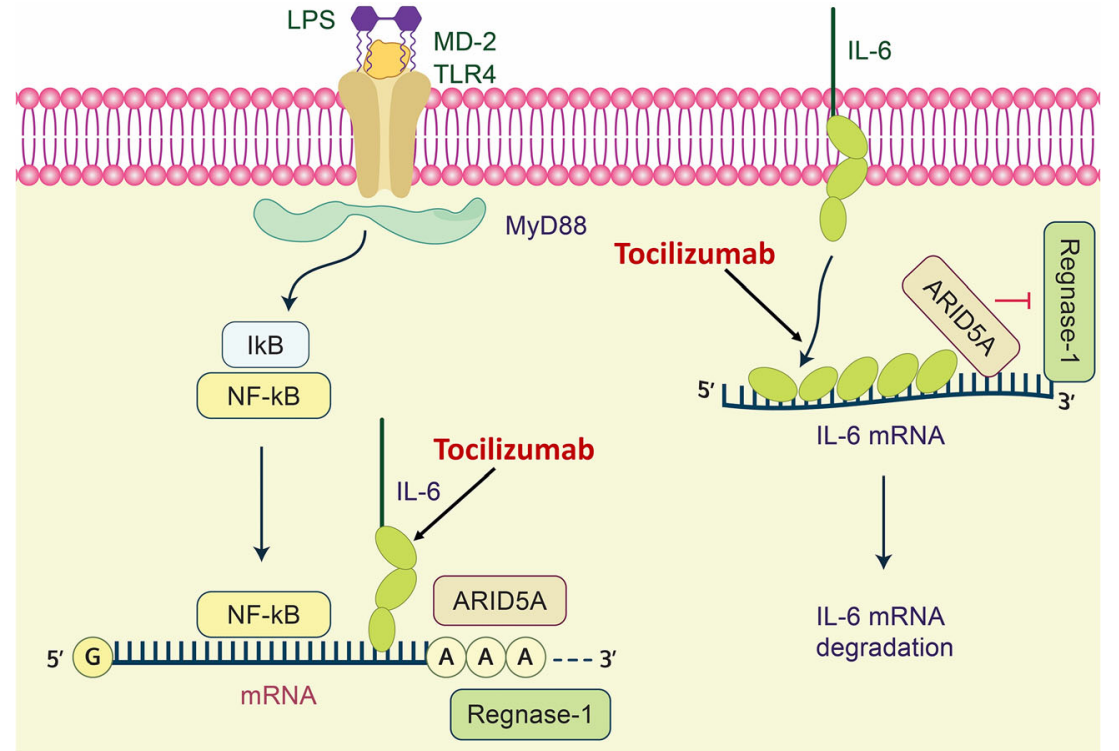

(Lammers et al. 2020). Inhibition of neutrophil apoptosis and emargination by glucocorticoid and the inhibition of phospholipase A2 are caused by dexamethasone, resulting in a decreased production of arachidonic acid derivatives and inhibition of NF- $\mathrm{KB}$ alongside different inflammatory transcription factors. Glucocorticoids induce the expression of antiinflammatory genes like IL-10. The effects of glucocorticoids mainly depend on the dose used, as lower dosages of glucocorticoids work as an antiinflammatory and higher dosage work as immunosuppressing agents (Solinas et al. 2020).

\section{Adverse side effects of the candidate antiviral drugs on human body}

\section{Remdesivir}

In the clinical trial of RDV against the SARS-CoV-2, scientists noted that the drug had some side effects in the human body, such as increased expression of liver enzymes, which can cause liver damage (Food and Administration 2020b). Recently, scientists also reported several side effects of RDV on the patients hospitalized with COVID-19 in the USA. Furthermore, several research studies of RDV on patients with COVID-19 have demonstrated a higher risk of an allergic reaction, low blood pressure, trouble breathing, and other human body abnormalities (Wang et al. 2020e) (Fig. 8). The scientists conducted the very first trial to investigate the effectiveness of 5 or 10 days of routine treatment with remdesivir for adults with mild pneumonia. Nausea, hypokalemia, and headache were more common than normal in the treatment group (Spinner et al. 2020). The risk of hepatic disorder among patients treated with remdesivir was increasing compared to hydroxychloroquine, lopinavir/ ritonavir, or tocilizumab, noticed by Montastruc et al. (Montastruc et al. 2020). We are aware of the information provided by Gilead in its EMA application for compassionate use of Ebola virus patients. Pool studies have observed adverse drug reactions (ADRs) in $<5 \%$ of subjects. Phlebitis, constipation, headache, ecchymosis, nausea, and pain in extremities have been the most frequent ADRs (Charan et al. 2021a, b).

\section{Tenofovir disoproxil fumarate}

Pharmacological studies of TDF have reported that there have been no side effects in the human body in general, and it is well endured (Grim and Romanelli 2003). Nevertheless, the clinical studies of TDF on COVID19 patients have shown that the TDF has some general side effects such as headache, dysentery, and vomiting of low to medium rapidity (Del Amo et al. 2020) (Fig. 8). Long-term TDF therapy is also linked to kidney damage in some patients, such as acute renal failure, proximal tubulopathy, and in extreme cases, Fanconi's syndrome (Cooper et al. 2010; Viganò et al. 2014). Treatment with tenofovir disoproxil fumarate results in minor decreases in glomerular filtration rate, which may be due to subclinical tubular injury (Hall et al. 2009; Mallet et al. 2015).

\section{Azithromycin}

It has been demonstrated that $\mathrm{AZ}$ is responsible for side effects, such as nausea and headaches (Kremer 2002). However, treating COVID-19 patients with AZ and HCQ combined has shown some severe side effects with potential life risks, including enhancing QT interspace and drug-mediated 


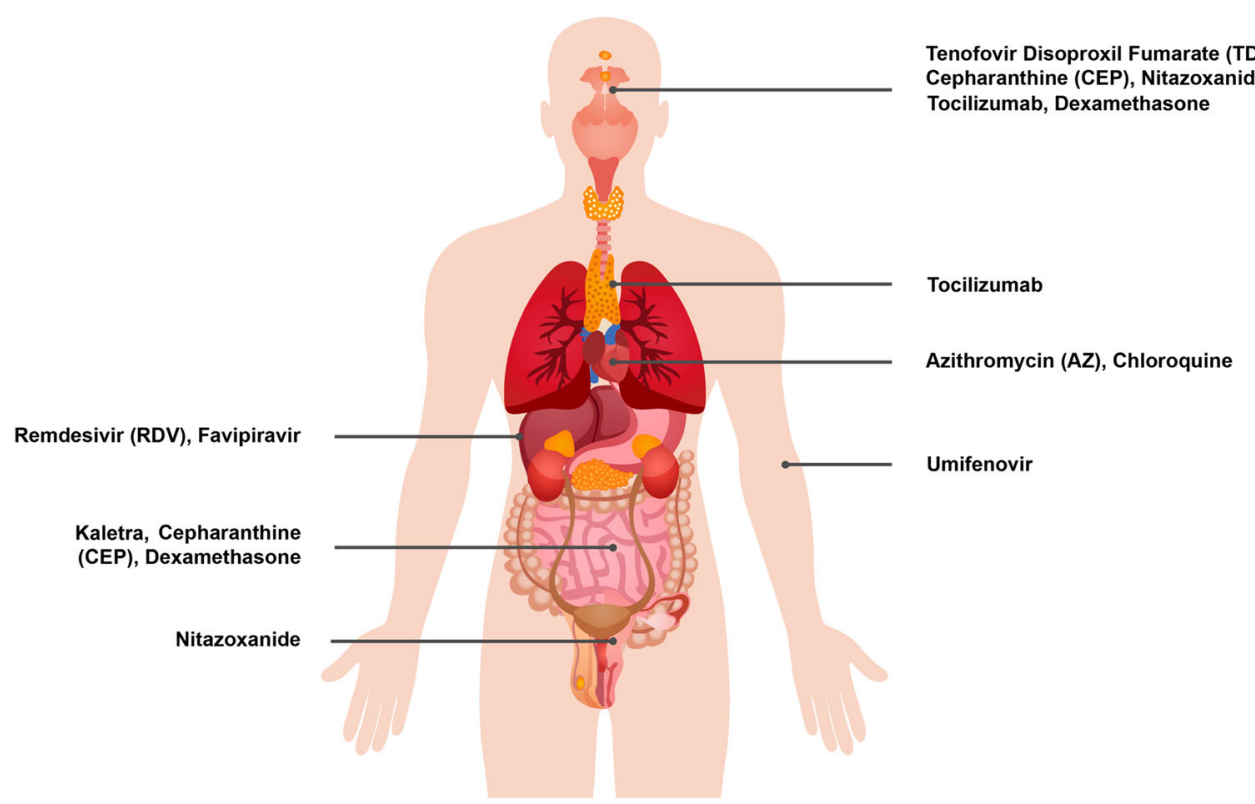

Fig. 8 Schematic representation of the primarily affected body parts from adverse side effects of the candidate antiviral drugs for SARS-CoV-2. Remdesivir (liver damage, high allergic reaction, and low blood pressure); tenofovir disoproxil fumarate (headache, dysentery, and vomiting); azithromycin (sudden cardiac failure, cardiovascular death, heart dysfunction); lopinavir/ritonavir (abdominal pain, nausea, headache); chloroquine (arrhythmias, heart failure, ventricular hypertrophy); baricitinib (decreased neutrophils as well as lymphocyte counts); cepharanthine (headaches, dizziness, and stomach ache); favipiravir (weight loss and increased serum concentration of liver function); ribavirin (nausea, weight loss); galidesivir (muscle weakness, vomiting, headache, allergic); umifenovir (allergic reaction); nitazoxanide (abdominal pain, nausea, diarrhea, headache); tocilizumab (upper respiratory tract infection, headache); dexamethasone (stomach pain or cramp, headaches).

asthenia, and diarrhea (Fig. 8). Eventually, the skin eruptions (rash), risks of hepatic damage (AST, ALT enzyme level elevated), pancreatitis, cutaneous eruptions, elevated triglycerides levels, and QT prolongation was also documented with the drug combination therapy with other drugs (Mangum and Graham 2001; Oldfield and Plosker 2006).

\section{Chloroquine}

Chloroquine manifests possible gastrointestinal symptoms, for instant, abdominal discomfort, vomiting, nausea, and diarrhea. It is important to highlight that chloroquine exhibited diverse cardiovascular problems as cardiac arrhythmias, hypotension, suppression of myocardial function, and vasodilation (Figure 8). Eventually, it capable to block potassium into the cells and also have an effect on the chloride channels which are present in cardiac myocytes (Mubagwa 2020). In the COVID-19 patient, chloroquine and hydroxychloroquine can cause arrhythmias, which can be reduced by combining it with other medical products, like azithromycin antibiotic, which has similar heart effects. Other studies 41 have reported severe rhythm complications associated with the use of chloroquine or hydroxychloroquine, especially in high doses or with azithromycin antibiotic. It was also known that cardiac side effects occurred mainly in women. Additionally, conduction disorders were the main side 
effects reported, while the other side effects included ventricular hypertrophy, hypokinesia, valvular dysfunction, and pulmonary arterial hypertension.

However, some minor neurological (like mental confusion, coma, and seizures) adverse effects were found from the chloroquine drug as well as it creates ocular problems, for example, corneal deposition, accommodation defect, and retinopathy (Leecharoen et al. 2007).

\section{Baricitinib}

Baricitinib was found to present several side effects in rheumatoid arthritis; these included decreased neutrophils as well as lymphocyte counts, elevated serum creatinine level (mainly creatine phosphokinase), reducing the hemoglobin level, increases in lipid parameters (i.e., LDL, HDL), and in some cases elevations in liver enzymes along with bilirubin (Jorgensen et al. 2020). Also, severe infections, tuberculosis, some adverse cardiovascular effects, and other major adverse side effects manifest during the administration of this drug on COVID-19 patients (Dougados et al. 2017). However, upper respiratory tract infection, nasopharyngitis, and headache are the most common side effect in COVID-19 patients when administrated the drug baricitinib (Jorgensen et al. 2020; Türsen et al. 2020) which reported that such a drug has several cutaneous toxicity profiles including skin rashes with allergy, skin cancers (melanoma and non-melanoma), viral reactivation (zona zoster and herpes simplex), urticaria, and angioedema.

\section{Cepharanthine}

The activation of caspase- 3 and caspase- 9 in CCA (Cholangiocarcinoma) cell lines was observed with the treatment of $20 \mu \mathrm{g} / \mathrm{ml}$ of CEP. As a result, CEP induces cell apoptosis in CCA cells via the caspase-3 and caspase-9 pathway (Ohnishi 1983). NF-kB plays a key function in cell survival and proliferation, but it was concluded that CEP suppresses the potential activity of NF- $\mathrm{KB}$; thus, it results in adverse effects on cell proliferation. Study has examined that CEP inhibits platelet aggregation. CEP has other side effects such as headaches, dizziness, and stomach discomfort (Rogosnitzky and Danks 2011b). Cepharanthine (CEP) possesses a few side effects on human body such as headaches, dizziness, and stomach ache (Fig. 8).

\section{Favipiravir}

Favipiravir exhibits several negative effects including the reduction of locomotive activity, anemia, vomiting, weight loss, increased vacuolization in hepatocytes, and increased serum concentration of liver function enzymes, such as total albumin, alkaline phosphatase, alanine aminotransferase, and aspartate aminotransferase (Fig. 8). It can also induce congenital disabilities and should not be used during pregnancy (Seneviratne et al. 2020; Hashemian et al. 2020). It has many side effects including weight loss and increased serum concentration of liver function enzymes, such as aspartate aminotransferase, alkaline phosphatase and alanine aminotransferase, diarrhea, decreased neutrophil count, and increased serum uric acid level (Jin et al. 2013) (Pilkington et al. 2020).

\section{Ribavirin}

Ribavirin alone and ribavirin, along with lopinavir and ritonavir, have been tested on SARS patients. The first group was out of 111 patients. The second group was out of 41 patients, where the trial results have demonstrated that the combined treatment lowers the acute respiratory distress syndrome (ARDS) risk and death (Dong et al. 2020). Some patients experienced some side effects of ribavirin like nausea, changes in weight, diarrhea, stomach ache, dizziness, blurred vision, and changes in sleep. Moreover, anemia can be caused by ribavirin, and it is a dose-dependent adverse effect. Reduced hemoglobin levels are also observed within the first 1-2 weeks included in the same therapy (Wishart et al. 2008) (Law et al. 2014). This drugs has also been found some side effects like nausea, weight loss or gain, diarrhea, stomach upset, dry skin, blurred vision, trouble sleeping, dizziness, headache, low appetite, and cough (Wishart et al. 2008; Law et al. 2014).

\section{Galidesivir}

It contains some adverse effects on human body; for example, muscle weakness, changes in vision, vomiting, headache, and allergic reaction have been observed on human body (Taylor et al. 2016) (Furuta et al. 2013b).

\section{Umifenovir}

As umifenovir interacts with both the viral protein and lipid, the viral replication cycle's downstream process might be affected. The Flaviviridae family of the virus replicates in a membranous-web sub-cellular compartment that requires interaction between protein and lipid, which can easily be affected by umifenovir (Blaising et al. 2014). Allergic reactions and nausea/vomiting have been reported by patients with acute hypersensitivity.

\section{Nitazoxanide}

Maturation inhibition of viral transcription factor IE2 (immediate early 2 ) and hemagglutinin is observed in nitazoxanide. The drug also activates the intracellular protein eukaryotic translation initiation factor $2 \alpha$ (Shakya et al. 2018). It shows 
various side effects, including abdominal pain, nausea, headache, change of urine, dizziness, diarrhea, and vomiting (Mahmoud et al. 2020).

\section{Tocilizumab}

Tocilizumab showed many antagonistic side effects in the human, for example, upper respiratory tract infection, headache, nasopharyngitis, injection site reaction, and hypertension (Alattar et al. 2020).

\section{Dexamethasone}

It has also shown some side effects, including stomach pain or cramps, headaches, dizziness, insomnia, changes in the menstrual cycle, weight gain, hyperglycemia, gastrointestinal hemorrhage, and psychosis (Theoharides and Conti 2020).

\section{Environmental implications of these candidate antiviral drugs}

The global market for of these candidate antiviral drugs has seen an unexpected rise in prices, fueled by initial reports on its efficacy in the treatment of COVID-19, resulting in an increase in production. These candidate drugs were generated in large quantities and have the potential to be persistent in the environment. Following the administration, the candidate drugs undergo a series of biotransformations and are excreted in both hydrolyzed and unconjugated forms by feces and urine. The wastewater from the pharmaceutical plants has to go through a series of treatments during processing, or the medication could end up in the water. Since these candidate drugs relate to a class of anthracycline compounds that are recalcitrant, toxic, persistent, teratogenic, and carcinogenic to aquatic species, it poses a significant long-term threat to the aquatic ecosystem, soil ecosystem, and finally human health hazard.

So many researchers have initially demonstrated a seasonal enhancement in antiviral medicinal products in wastewater treatment plants (WWTP) and obtaining waters during influenza pandemics (Azuma et al. 2015; Leknes et al. 2012; Singer et al. 2014). In the majority of studies based on the influenza treatment, oseltamivir and its metabolite, oseltamivir carboxylate, were investigated, with simulated and measured concentration levels in wastewater treatment plants reaching $1 \mu \mathrm{g} / \mathrm{l}$ and measured concentration levels in receiving water bodies getting up to $0.2 \mu \mathrm{ng} / \mathrm{l}$. These estimates and measurements correlate to levels of treatment for up to $40 \%$ of the human population, which is significantly lower than the levels of treatment that may be required in the event of a coronavirus pandemic. As the concentration level of several antiviral drugs rises at the same time over the same season, a variety of medications are likely being used mostly during an influenza pandemic (Azuma et al. 2015; Ellis 2010).

If the systems are improved for the elimination rate, the use of chloroquines is not known to cause significant environmental harm, even within pandemic situations. Additional remediation is achievable by planning the therapeutic regimen for medical treatment in advance of the event. However, despite the significant elimination of ivermectin by the WWTP, a high level of risk is anticipated. Even with the WHO Defined Daily Dosage (DDD) as human antiparasite, the utilization of $0.05 \%$ of humans in a particular aquatic ecosystem could have environmental effects. Government agencies such as the USFDA warned against the risk of distinctive Ivermectin self-treatment for COVID-19 after some pre-clinical research findings, which were provoked by false news (Tarazona et al. 2021). Our interpretation and projections have been indicated that this unauthorized use of antiviral drugs in the coronavirus pandemic may also have relatively significant environmental consequences. If dexamethasone is used only for hospitalized patients with chronic signs and symptoms, it is considered to pose a lower risk to the environment. In the case of azithromycin, widespread use for the treatment of COVID-19 patients would significantly raise environmental emissions, which already pose a risk in some of the countries (Grill et al. 2016; Loos et al. 2018; Rodriguez-Mozaz et al. 2020). Chloroquine act against the pathogens in the human body, but $70 \%$ of this drug are excreted from the body through the urine as well as feces, which are spread via the wastewater, sludge, and potentially detrimental to the soil and water microbiota (bacteria, protozoa). It is worth noting that these drugs affect the biota and are hazardous to soybean plants (Jjemba 2002). On the contrary, these non-biodegradable compounds have negative effects on the aquatic biota, mainly fish, and yield the toxicity of the underwater system (Zurita et al. 2005; Ramesh et al. 2018).

There has been an unexpected increase in demand for hydroxychloroquine (HCQ) on the international market, prompted by preliminary reports on its efficacy in treating COVID-19, likely to result in its manufacturing being scaled up. HCQ manufactured in large quantities can be resistant to biodegradation and biomagnification (Kumar et al. 2021). Following administration, HCQ goes through a series of biotransformations and is excreted in both hydrolyzed and glycosylated forms through the urine and feces. Throughout the manufacturing process, wastewater from pharmaceutical plats should perform various treatments to prevent the drug from entering the aquatic ecosystems. HCQ poses a significant chronic hazard to the marine ecosystem because it is an intransigent, toxic, persistent, teratogenic, and carcinogenic compound for aquatic animals. One recently conducted research study showed that chloroquine and HCQ kill the hair cells of the zebrafish lateral line when used for 1-24 h in different concentrations (Davis et al. 2020). 
Favipiravir has been linked to teratogenicity. Although the toxicity evidence for this drug is minimal, single dosage toxicity studies indicate that favipiravir is lethal for mice for $2,000 \mathrm{mg} / \mathrm{kg}$, dogs for $1000 \mathrm{mg} / \mathrm{kg}$, and rats for $2000 \mathrm{mg} / \mathrm{kg}$. Ribavirin is commonly used in China for nucleoside agents which possess the PNEC of less than $100 \mathrm{mg} / \mathrm{l}$ for green or blue green algae. The over dosages of ribavirin may affect the proper environmental growth for green algae. Umifenovir was found to show high chronic toxicity to aquatic organisms with predicted no effect concentration (PNEC) value of $9.3 \mathrm{ng} / \mathrm{l}$ (Kuroda et al. 2021). Also, receiving river waters suggest high ecotoxicological risk of umifenovir (Risk Quotients value of 1.7) (Kuroda et al. 2021). The half maximal effective concentration of tocilizumab (EC50) reported by the safety data sheet from the supplier shows no TCZ adverse effects for concentrations higher than 100 ppm (Race et al. 2020). Rapid biodegradability in sewage and surface waters and low ecotoxic characteristics were also reported by biodegradability and acute ecotoxicity studies (Race et al. 2020).

If the use is limited, low environmental concern is estimated for dexamethasone to use in the treatment with of hospital patients with severe clinical symptoms (Kuroda et al. 2021). For standard relevant endpoints, the NOEC (no observed effect concentrations) and LOEC (lowest observed effect concentration) values were in the $\mathrm{mg} / \mathrm{l}$ range, and sublethal effects were reported at much lower concentrations (Kuroda et al. 2021).

\section{Conclusion}

Since its emergence in Wuhan in 2019, SARS-CoV-2 has challenged countless countries and organizations around the world. The virus, whose pathogenesis and forms of transmission are more diverse than SARSCoV-1 and MERS, caused a brutal increase in morbidity and mortality rates in several regions, spreading rapidly across the six continents of the planet. Consequently, numerous lifestyle changes were necessary, from social isolation and movement restrictions to extremely stringent hygiene measures. However, despite the reduction in the number of cases in the locations where such measures were adopted, they were insufficient to contain the serious damage that the virus caused to our infrastructure. Due to the countless spontaneous mutations acquired over time, SARS-CoV-2 has shown its high potential for infectivity. Although, until now, such mutations have not been proven to be more lethal than their previous versions, the growing need to identify an effective treatment against the disease, which can cause everything from mild manifestations of airway infection to respiratory distress syndrome, is evident. Given the dedication of many researchers, research centers, and funding agencies around the world, at the end of 2020 , the first vaccine against COVID-19 was approved. To date, another 11 vaccines have been approved or authorized for emergency use, and many more are still being developed. However, the logistics of vaccination campaigns, especially in too populous countries, such as the USA, China, and India, associated with the lack of confirmed data on the long-term protection capacity of vaccines already approved, reinforces the aforementioned imminent need to identify effective treatment against this disease. Given the pandemic's urgent demand, it is required to reuse pre-existing drug therapies against other viral diseases.

Among the countless drugs on the market, this review identified the best therapeutic agents available on the market and whose effectiveness has been evaluated since the beginning of the pandemic. Information was presented on the respective mechanisms of action, clinical and epidemiological data obtained through cohorts, randomized and non-randomized studies, data regarding posology and maximum dosage, outcomes in preclinical studies of animal models of COVID-19, and history of use in other diseases and potential side effects as well as their possible environmental implications. The summarized information can provide an overview of the main points to be considered to assess whether or not a particular drug should be used off-label for COVID-19 treatment. Potential side effects, drug interactions, and environmental impacts must be taken into account in this choice, and the results of studies already carried out. The path to overcoming the pandemic will be arduous. However, the prospects for the future are positive when considering the use of drugs with the potential to mitigate disease severity and minimize community transmission. At the same time, we await the mass vaccination of the population.

Author contribution $\mathrm{PB}, \mathrm{MMH}$, and SAP conceived the original idea and designed the outlines of the study. PB, MMH, DD, ACDSC, NF, MAK, and FKJ wrote the first draft. PB and MHR designed the figure for the manuscript. MHR prepared the figures for the manuscript. PB, MMH, DD, SAP, SB, SP, and MKI edited the second draft. MSU made the critical comments and revision. All authors have read and approved the final manuscript.

Data availability Not applicable.

\section{Declarations}

Consent to participate Not applicable.

Consent for publication Not applicable.

Competing interests The authors declare no competing interests. 


\section{References}

Agostini ML, Andres EL, Sims AC, et al (2018) Coronavirus susceptibility to the antiviral remdesivir (GS-5734) is mediated by the viral polymerase and the proofreading exoribonuclease. MBio 9:

Alattar R, Ibrahim TB, Shaar SH et al (2020) Tocilizumab for the treatment of severe coronavirus disease 2019. J Med Virol 92:2042_ 2049

Al-Salama ZT, Scott LJ (2018) Baricitinib: a review in rheumatoid arthritis. Drugs 78:761-772

Al-Tawfiq JA, Al-Homoud AH, Memish ZA (2020) Remdesivir as a possible therapeutic option for the COVID-19. Travel Med Infect Dis 34:101615. https://doi.org/10.1016/j.tmaid.2020.101615

Anand K, Ziebuhr J, Wadhwani P et al (2003) Coronavirus main proteinase (3CLpro) structure: basis for design of anti-SARS drugs. Science 300:1763-1767. https://doi.org/10.1126/science.1085658

Arab-Zozani M, Hassanipour S, Ghoddoosi-Nejad D (2020) Favipiravir for treating patients with novel coronavirus (COVID-19): protocol for a systematic review and meta-analysis of randomised clinical trials. BMJ Open 10:e039730

Ashour HM, Elkhatib WF, Rahman MM, Elshabrawy HA (2020) Insights into the recent 2019 novel coronavirus (SARS-CoV-2) in light of past human coronavirus outbreaks. Pathog Basel Switz 9. https://doi.org/10.3390/pathogens 9030186

Asrani P, Hassan MI (2020) SARS-CoV-2 mediated lung inflammatory responses in host: targeting the cytokine storm for therapeutic interventions. Mol Cell Biochem 476:1-13

Azkur AK, Akdis M, Azkur D, Sokolowska M, Veen W, Brüggen MC, O'Mahony L, Gao Y, Nadeau K, Akdis CA (2020) Immune response to SARS-CoV-2 and mechanisms of immunopathological changes in COVID-19. Allergy 75:1564-1581. https://doi.org/10. 1111/all.14364

Azuma T, Ishiuchi H, Inoyama T, Teranishi Y, Yamaoka M, Sato T, Yamashita N, Tanaka H, Mino Y (2015) Detection of peramivir and laninamivir, new anti-influenza drugs, in sewage effluent and river waters in Japan. PLoS One 10:e0131412. https://doi.org/10. 1371/journal.pone.0131412

Babu YS, Chand P, Bantia S, Kotian P, Dehghani A, el-Kattan Y, Lin TH, Hutchison TL, Elliott AJ, Parker CD, Ananth SL, Horn LSL, Laver GW, Montgomery JA (2000) BCX-1812 (RWJ-270201): discovery of a novel, highly potent, orally active, and selective influenza neuraminidase inhibitor through structure-based drug design. J Med Chem 43:3482-3486

Bai Y, Yao L, Wei T, Tian F, Jin DY, Chen L, Wang M (2020) Presumed asymptomatic carrier transmission of COVID-19. JAMA 323: 1406-1407. https://doi.org/10.1001/jama.2020.2565

Bailly C (2019) Cepharanthine: An update of its mode of action, pharmacological properties and medical applications. Phytomedicine 62: 152956

Beigel JH, Tomashek KM, Dodd LE, Mehta AK, Zingman BS, Kalil AC, Hohmann E, Chu HY, Luetkemeyer A, Kline S, Lopez de Castilla D, Finberg RW, Dierberg K, Tapson V, Hsieh L, Patterson TF, Paredes R, Sweeney DA, Short WR et al (2020) Remdesivir for the treatment of Covid-19. N Engl J Med 383:1813-1826

Bessière F, Roccia H, Delinière A, Charrière R, Chevalier P, Argaud L, Cour M (2020) Assessment of QT intervals in a case series of patients with coronavirus disease 2019 (COVID-19) infection treated with hydroxychloroquine alone or in combination with azithromycin in an intensive care unit. JAMA Cardiol 5:1067-1069

Blaising J, Lévy PL, Polyak SJ, Stanifer M, Boulant S, Pécheur EI (2013) Arbidol inhibits viral entry by interfering with clathrin-dependent trafficking. Antivir Res 100:215-219. https://doi.org/10.1016/j. antiviral.2013.08.008

Blaising J, Polyak SJ, Pécheur E-I (2014) Arbidol as a broad-spectrum antiviral: an update. Antivir Res 107:84-94
Braz HLB, Silveira JA d M, Marinho AD et al (2020) In silico study of azithromycin, chloroquine and hydroxychloroquine and their potential mechanisms of action against SARS-CoV-2 infection. Int $\mathrm{J}$ Antimicrob Agents 56:106119. https://doi.org/10.1016/j. ijantimicag.2020.106119

Broekhuysen J, Stockis A, Lins RL, Graeve JD, Rossignol JF (2000) Nitazoxanide: pharmacokinetics and metabolism in man. Int J Clin Pharmacol Ther 38:387-394

Bronte V, Ugel S, Tinazzi E, Vella A, de Sanctis F, Canè S, Batani V, Trovato R, Fiore A, Petrova V, Hofer F, Barouni RM, Musiu C, Caligola S, Pinton L, Torroni L, Polati E, Donadello K, Friso S et al (2020) Baricitinib restrains the immune dysregulation in patients with severe COVID-19. J Clin Invest 130:6409-6416. https://doi. org/10.1172/JCI141772

Cai Q, Yang M, Liu D, Chen J, Shu D, Xia J, Liao X, Gu Y, Cai Q, Yang Y, Shen C, Li X, Peng L, Huang D, Zhang J, Zhang S, Wang F, Liu J, Chen L et al (2020) Experimental treatment with favipiravir for COVID-19: an open-label control study. Engineering 6:1192-1198

Callebaut C, Stepan G, Tian Y, Miller MD (2015) In vitro virology profile of tenofovir alafenamide, a novel oral prodrug of tenofovir with improved antiviral activity compared to that of tenofovir disoproxil fumarate. Antimicrob Agents Chemother 59:5909-5916

Cantini F, Niccoli L, Matarrese D, Nicastri E, Stobbione P, Goletti D (2020) Baricitinib therapy in COVID-19: a pilot study on safety and clinical impact. J Inf Secur 81:318-356

Cao B, Wang Y, Wen D, Liu W, Wang J, Fan G, Ruan L, Song B, Cai Y, Wei M, Li X, Xia J, Chen N, Xiang J, Yu T, Bai T, Xie X, Zhang L, $\mathrm{Li} \mathrm{C}$ et al (2020a) A trial of lopinavir-ritonavir in adults hospitalized with severe Covid-19. N Engl J Med 382:1787-1799. https://doi. org/10.1056/NEJMoa2001282

Cao Y-C, Deng Q-X, Dai S-X (2020b) Remdesivir for severe acute respiratory syndrome coronavirus 2 causing COVID-19: an evaluation of the evidence. Travel Med Infect Dis 35:101647. https://doi.org/ 10.1016/j.tmaid.2020.101647

Cascella M, Rajnik M, Cuomo A, et al (2020) Features, evaluation, and treatment of coronavirus. In: StatPearls. StatPearls Publishing, Treasure Island (FL)

Chapman TM, McGavin JK, Noble S (2003) Tenofovir disoproxil fumarate. Drugs 63:1597-1608

Charan J, Kaur RJ, Bhardwaj P, Haque M, Sharma P, Misra S, Godman B (2021a) Rapid review of suspected adverse drug events due to remdesivir in the WHO database; findings and implications. Expert Rev Clin Pharmacol 14:95-103

Charan J, Kaur RJ, Bhardwaj P, Haque M, Sharma P, Misra S, Godman B (2021b) Rapid review of suspected adverse drug events due to remdesivir in the WHO database; findings and implications. Expert Rev Clin Pharmacol 14:95-103

Chen W, Lan Y, Yuan X, Deng X, Li Y, Cai X, Li L, He R, Tan Y, Deng X, Gao M, Tang G, Zhao L, Wang J, Fan Q, Wen C, Tong Y, Tang $\mathrm{Y}, \mathrm{Hu} \mathrm{F}$ et al (2020) Detectable 2019-nCoV viral RNA in blood is a strong indicator for the further clinical severity. Emerg Microbes Infect 9:469-473

Cingolani A, Tummolo AM, Montemurro G, Gremese E, Larosa L, Cipriani MC, Pasciuto G, Liperoti R, Murri R, Pirronti T, Cauda R, Fantoni M, for COVID 2 Columbus Working Group, Bellieni A, Brandi V, Calabrese A, Calvello MR, Ciccullo A, Cingolani A et al (2020) Baricitinib as rescue therapy in a patient with COVID-19 with no complete response to sarilumab. Infection 48:767-771

Clososki GC, Soldi RA, da Silva RM et al (2020) Tenofovir disoproxil fumarate: new chemical developments and encouraging in vitro biological results for SARS-CoV-2. J Braz Chem Soc 31:1552-1556

Colson P, Rolain J-M, Raoult D (2020) Chloroquine for the 2019 novel coronavirus SARS-CoV-2. Int J Antimicrob Agents 55:105923

Cooper RD, Wiebe N, Smith N, Keiser P, Naicker S, Tonelli M (2010) Systematic review and meta-analysis: renal safety of tenofovir 
disoproxil fumarate in HIV-infected patients. Clin Infect Dis 51: 496-505

Costanzo M, De Giglio MA, Roviello GN (2020) SARS-CoV-2: recent reports on antiviral therapies based on lopinavir/ritonavir, darunavir/ umifenovir, hydroxychloroquine, remdesivir, favipiravir and other drugs for the treatment of the new coronavirus. Curr Med Chem 27: 4536-4541

Cramer CL, Patterson A, Alchakaki A, Soubani AO (2017) Immunomodulatory indications of azithromycin in respiratory disease: a concise review for the clinician. Postgrad Med 129:493-499

Damle B, Vourvahis M, Wang E, Leaney J, Corrigan B (2020) Clinical pharmacology perspectives on the antiviral activity of azithromycin and use in COVID-19. Clin Pharmacol Ther 108:201-211

Davis SN, Wu P, Camci ED, Simon JA, Rubel EW, Raible DW (2020) Chloroquine kills hair cells in zebrafish lateral line and murine cochlear cultures: implications for ototoxicity. Hear Res 395:108019. https://doi.org/10.1016/j.heares.2020.108019

De Clercq E (2007) Anti-HIV drugs. Verh-K Acad Voor Geneeskd Van Belg 69:81-104

de Souza WM, Romeiro MF, Fumagalli MJ et al (2017) Chapparvoviruses occur in at least three vertebrate classes and have a broad biogeographic distribution. J Gen Virol 98:225-229

Del Amo J, Polo R, Moreno S et al (2020) Incidence and severity of COVID-19 in HIV-positive persons receiving antiretroviral therapy: a cohort study. Ann Intern Med 173:536-541

Doi K, Ikeda M, Hayase N et al (2020) Nafamostat mesylate treatment in combination with favipiravir for patients critically ill with Covid-19: a case series. Crit Care 24:1-4

Dong L, Hu S, Gao J (2020) Discovering drugs to treat coronavirus disease 2019 (COVID-19). Drug Discov Ther 14:58-60. https:// doi.org/10.5582/ddt.2020.01012

Dougados M, van der Heijde D, Chen Y-C, Greenwald M, Drescher E, Liu J, Beattie S, Witt S, de la Torre I, Gaich C, Rooney T, Schlichting D, de Bono S, Emery P (2017) Baricitinib in patients with inadequate response or intolerance to conventional synthetic DMARDs: results from the RA-BUILD study. Ann Rheum Dis 76: $88-95$

Ellis JB (2010) Antiviral pandemic risk assessment for urban receiving waters. Water Sci Technol J Int Assoc Water Pollut Res 61:879884. https://doi.org/10.2166/wst.2010.002

Ershun Z, Yunhe F, Zhengkai W, Yongguo C, Naisheng Z, Zhengtao Y (2014) Cepharanthine attenuates lipopolysaccharide-induced mice mastitis by suppressing the NF-KB signaling pathway. Inflammation 37:331-337

Esbin MN, Whitney ON, Chong S, Maurer A, Darzacq X, Tjian R (2020) Overcoming the bottleneck to widespread testing: a rapid review of nucleic acid testing approaches for COVID-19 detection. RNA N Y N 26:771-783. https://doi.org/10.1261/rna.076232.120

Fan H-H, Wang L-Q, Liu W-L, An XP, Liu ZD, He XQ, Song LH, Tong YG (2020) Repurposing of clinically approved drugs for treatment of coronavirus disease 2019 in a 2019-novel coronavirus-related coronavirus model. Chin Med J 133:1051-1056. https://doi.org/ 10.1097/CM9.0000000000000797

Fatima U, Rizvi SSA, Fatima S, Hassan MI (2020) Impact of hydroxychloroquine/chloroquine in COVID-19 therapy: two sides of the coin. J Interferon Cytokine Res Off J Int Soc Interferon Cytokine Res 40:469-471. https://doi.org/10.1089/jir.2020.0105

Fehr AR, Perlman S (2015) Coronaviruses: an overview of their replication and pathogenesis. Methods Mol Biol Clifton NJ 1282:1-23. https://doi.org/10.1007/978-1-4939-2438-7_1

Fink SL, Vojtech L, Wagoner J et al (2018) The antiviral drug arbidol inhibits Zika virus. Sci Rep 8:1-9

Fleming SB (2016) Viral inhibition of the IFN-induced JAK/STAT signalling pathway: development of live attenuated vaccines by mutation of viral-encoded IFN-antagonists. Vaccines 4:23
Food, Administration D (2020a) Emergency use authorization for remdesivir

Food US, Administration D (2020b) Fact sheet for patients and parent/ caregivers Emergency Use Authorization (EUA) of remdesivir for coronavirus disease 2019 (COVID-19)

Furuta Y, Gowen BB, Takahashi K, Shiraki K, Smee DF, Barnard DL (2013a) Favipiravir (T-705), a novel viral RNA polymerase inhibitor. Antivir Res 100:446-454

Furuta Y, Gowen BB, Takahashi K, Shiraki K, Smee DF, Barnard DL (2013b) Favipiravir (T-705), a novel viral RNA polymerase inhibitor. Antivir Res 100:446-454

Gautret P, Lagier J-C, Parola P, Hoang VT, Meddeb L, Mailhe M, Doudier B, Courjon J, Giordanengo V, Vieira VE, Tissot Dupont $\mathrm{H}$, Honoré S, Colson $\mathrm{P}$, Chabrière E, la Scola $\mathrm{B}$, Rolain JM, Brouqui P, Raoult D (2020a) Hydroxychloroquine and azithromycin as a treatment of COVID-19: results of an open-label non-randomized clinical trial. Int J Antimicrob Agents 56:105949. https://doi.org/10. 1016/j.ijantimicag.2020.105949

Gautret P, Lagier J-C, Parola P, Hoang VT, Meddeb L, Mailhe M, Doudier B, Courjon J, Giordanengo V, Vieira VE, Tissot Dupont H, Honoré S, Colson P, Chabrière E, la Scola B, Rolain JM, Brouqui P, Raoult D (2020b) Hydroxychloroquine and azithromycin as a treatment of COVID-19: results of an open-label non-randomized clinical trial. Int J Antimicrob Agents 56:105949

Gengiah TN, Baxter C, Mansoor LE, Kharsany ABM, Abdool Karim SS (2012) A drug evaluation of 1\% tenofovir gel and tenofovir disoproxil fumarate tablets for the prevention of HIV infection. Expert Opin Investig Drugs 21:695-715

Gordon CJ, Tchesnokov EP, Feng JY, Porter DP, Götte M (2020) The antiviral compound remdesivir potently inhibits RNA-dependent RNA polymerase from Middle East respiratory syndrome coronavirus. J Biol Chem 295:4773-4779

Gordon SC, Krastev Z, Horban A, Petersen J, Sperl J, Dinh P, Martins EB, Yee LJ, Flaherty JF, Kitrinos KM, Rustgi VK, Marcellin P (2013) Efficacy of tenofovir disoproxil fumarate at 240 weeks in patients with chronic hepatitis B with high baseline viral load. Hepatology 58:505-513

Grill G, Khan U, Lehner B, Nicell J, Ariwi J (2016) Risk assessment of down-the-drain chemicals at large spatial scales: Model development and application to contaminants originating from urban areas in the Saint Lawrence River Basin. Sci Total Environ 541:825-838. https://doi.org/10.1016/j.scitotenv.2015.09.100

Grim SA, Romanelli F (2003) Tenofovir disoproxil fumarate. Ann Pharmacother 37:849-859

Group RC (2020) Dexamethasone in hospitalized patients with Covid19 - preliminary report. N Engl J Med

Guaraldi G, Meschiari M, Cozzi-Lepri A, Milic J, Tonelli R, Menozzi M, Franceschini E, Cuomo G, Orlando G, Borghi V, Santoro A, di Gaetano M, Puzzolante C, Carli F, Bedini A, Corradi L, Fantini R, Castaniere I, Tabbì L et al (2020) Tocilizumab in patients with severe COVID-19: a retrospective cohort study. Lancet Rheumatol 2:e474-e484

Hall AM, Edwards SG, Lapsley M, Connolly JO, Chetty K, O'Farrell S, Unwin RJ, Williams IG (2009) Subclinical tubular injury in HIVinfected individuals on antiretroviral therapy: a cross-sectional analysis. Am J Kidney Dis 54:1034-1042

Hasana S, Hossain MF, Jalouli M, Kabir MT, Uddin MG, Wahed MII, Behl T, Bin-Jumah MN, Abdel-Daim MM, Aleya L, Uddin MS (2021) Genetic Diversity of SARS-CoV2 and Environmental Settings: Possible Association with Neurological Disorders. Mol Neurobio 58:1917-1931. https://doi.org/10.1007/s12035-02002239-z

Hashemian SM, Farhadi T, Velayati AA (2020) A review on favipiravir: the properties, function, and usefulness to treat COVID-19. Expert Rev Anti-Infect Ther:1-9 
Haviernik J, Štefánik M, Fojtíková M, Kali S, Tordo N, Rudolf I, Hubálek Z, Eyer L, Ruzek D (2018) Arbidol (Umifenovir): a broad-spectrum antiviral drug that inhibits medically important arthropod-borne flaviviruses. Viruses 10:184

Hofmann WP, Herrmann E, Sarrazin C, Zeuzem S (2008) Ribavirin mode of action in chronic hepatitis $\mathrm{C}$ : from clinical use back to molecular mechanisms. Liver Int 28:1332-1343

Homolak J, Kodvanj I (2020) Widely available lysosome targeting agents should be considered as potential therapy for COVID-19. Int $\mathrm{J}$ Antimicrob Agents 56:106044

Hu B, Guo H, Zhou P, Shi Z-L (2020) Characteristics of SARS-CoV-2 and COVID-19. Nat Rev Microbiol 19:141-154. https://doi.org/10. 1038/s41579-020-00459-7

Huang C, Wang Y, Li X, Ren L, Zhao J, Hu Y, Zhang L, Fan G, Xu J, Gu X, Cheng Z, Yu T, Xia J, Wei Y, Wu W, Xie X, Yin W, Li H, Liu M et al (2020a) Clinical features of patients infected with 2019 novel coronavirus in Wuhan, China. Lancet Lond Engl 395:497-506. https://doi.org/10.1016/S0140-6736(20)30183-5

Huang J, Song W, Huang H, Sun Q (2020b) Pharmacological therapeutics targeting RNA-dependent RNA polymerase, proteinase and spike protein: from mechanistic studies to clinical trials for COVID-19. J Clin Med 9:1131

Hulseberg CE, Fénéant L, Wijs KMS et al (2019) Arbidol and other lowmolecular-weight drugs that inhibit Lassa and Ebola viruses. J Virol 93. https://doi.org/10.1128/JVI.02185-18

Jin Y, Yang H, Ji W, Wu W, Chen S, Zhang W, Duan G (2020) Virology, epidemiology, pathogenesis, and control of COVID-19. Viruses 12. https://doi.org/10.3390/v12040372

Jin Z, Smith LK, Rajwanshi VK, Kim B, Deval J (2013) The ambiguous base-pairing and high substrate efficiency of T-705 (favipiravir) ribofuranosyl 5'-triphosphate towards influenza A virus polymerase. PLoS One 8:e68347

Jjemba PK (2002) The effect of chloroquine, quinacrine, and metronidazole on both soybean plants and soil microbiota. Chemosphere 46: 1019-1025

Johnson RM, Vinetz JM (2020) Dexamethasone in the management of covid-19. British Medical Journal Publishing Group

Jorgensen SC, Tse CL, Burry L, Dresser LD (2020) Baricitinib: a review of pharmacology, safety, and emerging clinical experience in COVID-19. Pharmacother J Hum Pharmacol Drug Ther 40:843856

Khalaf K, Papp N, Chou JT-T, Hana D, Mackiewicz A, Kaczmarek M (2020) SARS-CoV-2: pathogenesis, and advancements in diagnostics and treatment. Front Immunol 11:570927. https://doi.org/10. 3389/fimmu.2020.570927

Kim DE, Min JS, Jang MS, Lee J, Shin Y, Park C, Song J, Kim H, Kim S, Jin YH, Kwon S (2019) Natural bis-benzylisoquinoline alkaloidstetrandrine, fangchinoline, and cepharanthine, inhibit human coronavirus OC43 infection of MRC-5 human lung cells. Biomolecules 9:696

Ko W-C, Rolain J-M, Lee N-Y, Chen PL, Huang CT, Lee PI, Hsueh PR (2020) Arguments in favour of remdesivir for treating SARS-CoV-2 infections. Int J Antimicrob Agents 55:105933

Kolluri NL, Murthy D (2021) CoVerifi: A COVID-19 news verification system. Online Soc Netw Media 22:100123. https://doi.org/10. 1016/j.osnem.2021.100123

Kremer CJ (2002) Azithromycin - a new macrolide. Prim Care Update ObGyns 9:174-175

Kumar R, Sharma A, Srivastava JK, Siddiqui MH, Uddin MS, Aleya L (2021) Hydroxychloroquine in COVID-19: therapeutic promises, current status, and environmental implications. Environ Sci Pollut Res Int 28:40431-40444. https://doi.org/10.1007/s11356-02012200-1

Kumar R, Srivastava JK, Singh R, Siddiqui MH, Mansouri RA, Abdulhakim JA, Bin-Jumah MN, Alkahtani S, Abdel-Daim MM, Uddin MS (2020) Available Compounds With Therapeutic
Potential Against COVID-19: Antimicrobial Therapies Supportive Care and Probable Vaccines. Frontiers Pharmacol 11:582025. https://doi.org/10.3389/fphar.2020.582025

Kuroda K, Li C, Dhangar K, Kumar M (2021) Predicted occurrence, ecotoxicological risk and environmentally acquired resistance of antiviral drugs associated with COVID-19 in environmental waters. Sci Total Environ 776:145740

Lammers T, Sofias AM, van der Meel R, Schiffelers R, Storm G, Tacke F, Koschmieder S, Brümmendorf TH, Kiessling F, Metselaar JM (2020) Dexamethasone nanomedicines for COVID-19. Nat Nanotechnol 15:622-624

Lane JCE, Weaver J, Kostka K, Duarte-Salles T, Abrahao MTF, Alghoul $\mathrm{H}$, Alser O, Alshammari TM, Biedermann P, Banda JM, Burn E, Casajust P, Conover MM, Culhane AC, Davydov A, DuVall S, Dymshyts D, Fernandez-Bertolin S, Fišter K et al (2020) Risk of hydroxychloroquine alone and in combination with azithromycin in the treatment of rheumatoid arthritis: a multinational, retrospective study. Lancet Rheumatol 2:e698-e711. https://doi.org/10.1016/ S2665-9913(20)30276-9

Law V, Knox C, Djoumbou Y, Jewison T, Guo AC, Liu Y, Maciejewski A, Arndt D, Wilson M, Neveu V, Tang A, Gabriel G, Ly C, Adamjee S, Dame ZT, Han B, Zhou Y, Wishart DS (2014) DrugBank 4.0: shedding new light on drug metabolism. Nucleic Acids Res 42:D1091-D1097

Leecharoen S, Wangkaew S, Louthrenoo W (2007) Ocular side effects of chloroquine in patients with rheumatoid arthritis, systemic lupus erythematosus and scleroderma. J-Med Assoc Thail 90:52

Leknes H, Sturtzel IE, Dye C (2012) Environmental release of oseltamivir from a Norwegian sewage treatment plant during the 2009 influenza A (H1N1) pandemic. Sci Total Environ 414:632-638. https://doi. org/10.1016/j.scitotenv.2011.11.004

Li C, Zu S, Deng Y-Q, et al (2019) Azithromycin protects against Zika virus infection by upregulating virus-induced type I and III interferon responses Antimicrob Agents Chemother 63:

Li M, Liu Y, Wei F, Shen MX, Zhong Y, Li S, Chen LJ, Ma N, Liu BY, Mao YD, Li N, Hou W, Xiong HR, Yang ZQ (2018) Antiviral activity of Arbidol hydrochloride against herpes simplex virus I in vitro and in vivo. Int J Antimicrob Agents 51:98-106

Li Y, Xie Z, Lin W, Cai W, Wen C, Guan Y, Mo X, Wang J, Wang Y, Peng P, Chen X, Hong W, Xiao G, Liu J, Zhang L, Hu F, Li F, Zhang F, Deng X, Li L (2020) Efficacy and safety of lopinavir/ ritonavir or Arbidol in adult patients with mild/moderate COVID19: an exploratory randomized controlled trial. Med 1:105-113

Lighter J, Raabe V (2020) Azithromycin should not be used to treat COVID-19. In: Open forum infectious diseases. Oxford University Press US, p ofaa207

Lode H, Borner K, Koeppe P, Schaberg T (1996) Azithromycin - review of key chemical, pharmacokinetic and microbiological features. J Antimicrob Chemother 37:1-8

Loos R, Marinov D, Sanseverino I et al (2018) Review of the 1st Watch List under the Water Framework Directive and recommendations for the 2nd Watch List. Luxemb Publ Off Eur Union

Lu H (2020a) Drug treatment options for the 2019-new coronavirus (2019-nCoV). Biosci Trends 14:69-71

Lu H (2020b) Drug treatment options for the 2019-new coronavirus (2019-nCoV). Biosci Trends 14:69-71. https://doi.org/10.5582/bst. 2020.01020

Mahmoud DB, Shitu Z, Mostafa A (2020) Drug repurposing of nitazoxanide: can it be an effective therapy for COVID-19? J Genet Eng Biotechnol 18:1-10

Malik YA (2020) Properties of Coronavirus and SARS-CoV-2. Malays J Pathol 42:3-11

Mallet V, Schwarzinger M, Vallet-Pichard A, Fontaine H, Corouge M, Sogni P, Pol S (2015) Effect of nucleoside and nucleotide analogues on renal function in patients with chronic hepatitis B virus monoinfection. Clin Gastroenterol Hepatol 13:1181-1188 
Mangum EM, Graham KK (2001) Lopinavir-ritonavir: a new protease inhibitor. Pharmacother J Hum Pharmacol Drug Ther 21:13521363

Menzel M, Akbarshahi H, Bjermer L, Uller L (2016) Azithromycin induces anti-viral effects in cultured bronchial epithelial cells from COPD patients. Sci Rep 6:28698. https://doi.org/10.1038/ srep28698

Mercuro NJ, Yen CF, Shim DJ, Maher TR, McCoy CM, Zimetbaum PJ, Gold HS (2020) Risk of QT interval prolongation associated with use of hydroxychloroquine with or without concomitant azithromycin among hospitalized patients testing positive for coronavirus disease 2019 (COVID-19). JAMA Cardiol 5:1036-1041

Million M, Lagier J-C, Gautret P, Colson P, Fournier PE, Amrane S, Hocquart M, Mailhe M, Esteves-Vieira V, Doudier B, Aubry C, Correard F, Giraud-Gatineau A, Roussel Y, Berenger C, Cassir N, Seng P, Zandotti C, Dhiver C et al (2020) Early treatment of COVID-19 patients with hydroxychloroquine and azithromycin: a retrospective analysis of 1061 cases in Marseille, France. Travel Med Infect Dis 35:101738. https://doi.org/10.1016/j.tmaid.2020. 101738

Montastruc F, Thuriot S, Durrieu G (2020) Hepatic disorders with the use of remdesivir for coronavirus 2019. Clin Gastroenterol Hepatol 18: $2835-2836$

Mousavizadeh L, Ghasemi S (2020) Genotype and phenotype of COVID-19: their roles in pathogenesis. J Microbiol Immunol Infect Wei Mian Yu Gan Ran Za Zhi 10:159-163. https://doi.org/ 10.1016/j.jmii.2020.03.022

Mubagwa K (2020) Chloroquine cardiac effects and toxicity. A short update Int J Antimicrob Agents 106057

Nabil A, Uto K, Elshemy MM et al (2020) Current coronavirus (SARSCoV-2) epidemiological, diagnostic and therapeutic approaches: an updated review until June 2020. EXCLI J 19:992-1016. https://doi. org/10.17179/excli2020-2554

Nagatsuka S, Nakazawa T (1982) Effects of membrane-stabilizing agents, cholesterol and cepharanthin, on radiation-induced lipid peroxidation and permeability in liposomes. Biochim Biophys Acta BBA-Biomembr 691:171-177

Nakagawa K, Lokugamage KG, Makino S (2016) Viral and cellular mRNA translation in coronavirus-infected cells. Adv Virus Res 96:165-192

Noedl H, Krudsood S, Leowattana W, Tangpukdee N, Thanachartwet W, Looareesuwan S, Miller RS, Fukuda M, Jongsakul K, Yingyuen K, Sriwichai S, Ohrt C, Knirsch C (2007) In vitro antimalarial activity of azithromycin, artesunate, and quinine in combination and correlation with clinical outcome. Antimicrob Agents Chemother 51: 651-656

Ohnishi ST (1983) Inhibition of the in vitro formation of irreversibly sickled cells by cepharanthine. Br J Haematol 55:665-671

OKAMOTO M, ONO M, BABA M (1998) Potent inhibition of HIV type 1 replication by an antiinflammatory alkaloid, cepharanthine, in chronically infected monocytic cells. AIDS Res Hum Retrovir 14: 1239-1245

Oldfield V, Plosker GL (2006) Lopinavir/ritonavir. Drugs 66:1275-1299

Paudel KR, Karki R, Kim D-W (2016) Cepharanthine inhibits in vitro VSMC proliferation and migration and vascular inflammatory responses mediated by RAW264. 7. Toxicol in Vitro 34:16-25

Pilkington V, Pepperrell T, Hill A (2020) A review of the safety of favipiravir-a potential treatment in the COVID-19 pandemic? J Virus Erad 6:45-51

Pillay TS (2020) Gene of the month: the 2019-nCoV/SARS-CoV-2 novel coronavirus spike protein. J Clin Pathol 73:366-369. https://doi.org/ 10.1136/jclinpath-2020-206658

Plantone D, Koudriavtseva T (2018) Current and future use of chloroquine and hydroxychloroquine in infectious, immune, neoplastic, and neurological diseases: a mini-review. Clin Drug Investig 38: 653-671
Principi N, Esposito S (2020) Chloroquine or hydroxychloroquine for prophylaxis of COVID-19. Lancet Infect Dis 20:1118. https://doi. org/10.1016/S1473-3099(20)30296-6

Pruijssers AJ, George AS, Schäfer A, Leist SR, Gralinksi LE, Dinnon KH III, Yount BL, Agostini ML, Stevens LJ, Chappell JD, Lu X, Hughes TM, Gully K, Martinez DR, Brown AJ, Graham RL, Perry JK, du Pont V, Pitts J et al (2020) Remdesivir inhibits SARS-CoV-2 in human lung cells and chimeric SARS-CoV expressing the SARS-CoV-2 RNA polymerase in mice. Cell Rep 32: 107940

Pundi K, Perino AC, Harrington RA, Krumholz HM, Turakhia MP (2020) Characteristics and strength of evidence of COVID-19 studies registered on ClinicalTrials. gov. JAMA Intern Med 180:13981400

Race M, Ferraro A, Galdiero E, Guida M, Núñez-Delgado A, Pirozzi F, Siciliano A, Fabbricino M (2020) Current emerging SARS-CoV-2 pandemic: potential direct/indirect negative impacts of virus persistence and related therapeutic drugs on the aquatic compartments. Environ Res 188:109808

Ramesh M, Anitha S, Poopal RK, Shobana C (2018) Evaluation of acute and sublethal effects of chloroquine $(\mathrm{C} 18 \mathrm{H} 26 \mathrm{CIN} 3)$ on certain enzymological and histopathological biomarker responses of a freshwater fish Cyprinus carpio. Toxicol Rep 5:18-27

Ray AS, Fordyce MW, Hitchcock MJ (2016) Tenofovir alafenamide: a novel prodrug of tenofovir for the treatment of human immunodeficiency virus. Antivir Res 125:63-70

Robba C, Battaglini D, Pelosi P, Rocco PRM (2020) Multiple organ dysfunction in SARS-CoV-2: MODS-CoV-2. Expert Rev Respir Med 14:865-868. https://doi.org/10.1080/17476348.2020.1778470

Rodriguez-Mozaz S, Vaz-Moreira I, Varela Della Giustina S, Llorca M, Barceló D, Schubert S, Berendonk TU, Michael-Kordatou I, FattaKassinos D, Martinez JL, Elpers C, Henriques I, Jaeger T, Schwartz T, Paulshus E, O'Sullivan K, Pärnänen KMM, Virta M, Do TT et al (2020) Antibiotic residues in final effluents of European wastewater treatment plants and their impact on the aquatic environment. Environ Int 140:105733. https://doi.org/10.1016/j.envint.2020. 105733

Rogosnitzky M, Danks R (2011a) Therapeutic potential of the biscoclaurine alkaloid, cepharanthine, for a range of clinical conditions. Pharmacol Rep 63:337-347

Rogosnitzky M, Danks R (2011b) Therapeutic potential of the biscoclaurine alkaloid, cepharanthine, for a range of clinical conditions. Pharmacol Rep 63:337-347

Rothan HA, Byrareddy SN (2020) The epidemiology and pathogenesis of coronavirus disease (COVID-19) outbreak. J Autoimmun 109: 102433. https://doi.org/10.1016/j.jaut.2020.102433

Ruane PJ, DeJesus E, Berger D, Markowitz M, Bredeek UF, Callebaut C, Zhong L, Ramanathan S, S. Rhee M, Fordyce MW, Yale K (2013) Antiviral activity, safety, and pharmacokinetics/pharmacodynamics of tenofovir alafenamide as 10-day monotherapy in HIV-1-positive adults. JAIDS J Acquir Immune Defic Syndr 63:449-455

Sahraei Z, Shabani M, Shokouhi S, Saffaei A (2020) Aminoquinolines against coronavirus disease 2019 (COVID-19): chloroquine or hydroxychloroquine. Int J Antimicrob Agents 55:105945

Sakaguchi S, Furusawa S, Wu J, Nagata K (2007) Preventive effects of a biscoclaurine alkaloid, cepharanthine, on endotoxin or tumor necrosis factor- $\alpha$-induced septic shock symptoms: involvement of from cell death in L929 cells and nitric oxide production in raw 264.7 cells. Int Immunopharmacol 7:191-197

Seneviratne SL, Abeysuriya V, De Mel S et al (2020) Favipiravir in COVID-19. Int J Progress Sci Technol 19:143-145

Shakya A, Bhat HR, Ghosh SK (2018) Update on nitazoxanide: a multifunctional chemotherapeutic agent. Curr Drug Discov Technol 15: 201-213

Singer AC, Järhult JD, Grabic R, Khan GA, Lindberg RH, Fedorova G, Fick J, Bowes MJ, Olsen B, Söderström H (2014) Intra- and inter- 
pandemic variations of antiviral, antibiotics and decongestants in wastewater treatment plants and receiving rivers. PLoS One 9: e108621. https://doi.org/10.1371/journal.pone.0108621

Singh AK, Singh A, Singh R, Misra A (2020) Remdesivir in COVID-19: a critical review of pharmacology, pre-clinical and clinical studies. Diabetes Metab Syndr Clin Res Rev 14:641-648

Solinas C, Perra L, Aiello M, Migliori E, Petrosillo N (2020) A critical evaluation of glucocorticoids in the treatment of severe COVID-19. Cytokine Growth Factor Rev 54:8-23

Spinner CD, Gottlieb RL, Criner GJ, Arribas López JR, Cattelan AM, Soriano Viladomiu A, Ogbuagu O, Malhotra P, Mullane KM, Castagna A, Chai LYA, Roestenberg M, Tsang OTY, Bernasconi E, le Turnier P, Chang SC, SenGupta D, Hyland RH, Osinusi AO et al (2020) Effect of remdesivir vs standard care on clinical status at 11 days in patients with moderate COVID-19: a randomized clinical trial. JAMA 324:1048-1057. https://doi.org/10.1001/jama.2020. 16349

St-Jean JR, Jacomy H, Desforges M et al (2004) Human respiratory coronavirus OC43: genetic stability and neuroinvasion. J Virol 78: 8824-8834

Tanaka T, Narazaki M, Kishimoto T (2014) IL-6 en la inflamación, la inmunidad, y la enfermedad. Cold Spring Harb Perspect Biol 6: a016295

Tarazona JV, Martínez M, Martínez M-A, Anadón A (2021) Environmental impact assessment of COVID-19 therapeutic solutions. A prospective analysis. Sci Total Environ 778:146257

Taylor PC, Weinblatt ME, Burmester GR, Rooney TP, Witt S, Walls CD, Issa M, Salinas CA, Saifan C, Zhang X, Cardoso A, González-Gay MA, Takeuchi T (2019) Cardiovascular safety during treatment with baricitinib in rheumatoid arthritis. Arthritis Rheum 71:1042-1055

Taylor R, Kotian P, Warren T, Panchal R, Bavari S, Julander J, Dobo S, Rose A, el-Kattan Y, Taubenheim B, Babu Y, Sheridan WP (2016) BCX4430-a broad-spectrum antiviral adenosine nucleoside analog under development for the treatment of Ebola virus disease. J Infect Public Health 9:220-226

Tchesnokov EP, Feng JY, Porter DP, Götte M (2019a) Mechanism of inhibition of Ebola virus RNA-dependent RNA polymerase by remdesivir. Viruses 11:326. https://doi.org/10.3390/v11040326

Tchesnokov EP, Feng JY, Porter DP, Götte M (2019b) Mechanism of inhibition of Ebola virus RNA-dependent RNA polymerase by remdesivir. Viruses 11:326

Teissier E, Zandomeneghi G, Loquet A, Lavillette D, Lavergne JP, Montserret R, Cosset FL, Böckmann A, Meier BH, Penin F, Pécheur EI (2011) Mechanism of inhibition of enveloped virus membrane fusion by the antiviral drug Arbidol. PLoS One 6: e15874. https://doi.org/10.1371/journal.pone.0015874

Tempestilli M, Caputi P, Avataneo V, Notari S, Forini O, Scorzolini L, Marchioni L, Ascoli Bartoli T, Castilletti C, Lalle E, Capobianchi MR, Nicastri E, D'Avolio A, Ippolito G, Agrati C, the COVID 19 INMI Study Group, Abbonizio MA, Agrati C, Albarello F et al (2020) Pharmacokinetics of remdesivir and GS-441524 in two critically ill patients who recovered from COVID-19. J Antimicrob Chemother 75:2977-2980

Theoharides TC, Conti P (2020) Dexamethasone for COVID-19? Not so fast. J Biol Regul Homeost Agents 34:10-23812

Titanji BK, Farley MM, Mehta A, Connor-Schuler R, Moanna A, Cribbs SK, O'Shea J, DeSilva K, Chan B, Edwards A, Gavegnano C, Schinazi RF, Marconi VC (2020) Use of baricitinib in patients with moderate and severe COVID-19. Clin Infect Dis Off Publ Infect Dis Soc Am 72:1247-1250. https://doi.org/10.1093/cid/ciaa879

Torres D d A, Ribeiro L d CB, Riello AP d FL et al (2021) Reinfection of COVID-19 after 3 months with a distinct and more aggressive clinical presentation: case report. J Med Virol 93:1857-1859. https:// doi.org/10.1002/jmv.26637

Touret F, de Lamballerie X (2020) Of chloroquine and COVID-19. Antivir Res 177:104762
Türsen Ü, Türsen B, Lotti T (2020) Cutaneous side-effects of the potential COVID-19 drugs. Dermatol Ther 33:e13476

Tyteca D, Van Der Smissen P, Mettlen M et al (2002) Azithromycin, a lysosomotropic antibiotic, has distinct effects on fluid-phase and receptor-mediated endocytosis, but does not impair phagocytosis in J774 macrophages. Exp Cell Res 281:86-100

van der Hoek L, Pyrc K, Jebbink MF, Vermeulen-Oost W, Berkhout RJM, Wolthers KC, Wertheim-van Dillen PME, Kaandorp J, Spaargaren J, Berkhout B (2004) Identification of a new human coronavirus. Nat Med 10:368-373. https://doi.org/10.1038/nm1024

Viganò M, Brocchieri A, Spinetti A, Zaltron S, Mangia G, Facchetti F, Fugazza A, Castelli F, Colombo M, Lampertico P (2014) Tenofovirinduced Fanconi syndrome in chronic hepatitis B monoinfected patients that reverted after tenofovir withdrawal. J Clin Virol 61:600 603

Walls AC, Park Y-J, Tortorici MA, Wall A, McGuire AT, Veesler D (2020) Structure, function, and antigenicity of the SARS-CoV-2 Spike Glycoprotein. Cell 181, 181:281, 281-292.e6, 292.e6. https://doi.org/10.1016/j.cell.2020.02.058

Wang M, Cao R, Zhang L, Yang X, Liu J, Xu M, Shi Z, Hu Z, Zhong W, Xiao G (2020a) Remdesivir and chloroquine effectively inhibit the recently emerged novel coronavirus $(2019-\mathrm{nCoV})$ in vitro. Cell Res 30:269-271. https://doi.org/10.1038/s41422-020-0282-0

Wang Q, Wu J, Wang H, Gao Y, Liu Q, Mu A, Ji W, Yan L, Zhu Y, Zhu C, Fang X, Yang X, Huang Y, Gao H, Liu F, Ge J, Sun Q, Yang X, $\mathrm{Xu} \mathrm{W}$ et al (2020b) Structural basis for RNA replication by the SARS-CoV-2 Polymerase. Cell 182:417-428.e13. https://doi.org/ 10.1016/j.cell.2020.05.034

Wang R, Zhang X, Irwin DM, Shen Y (2020c) Emergence of SARS-like coronavirus poses new challenge in China. J Inf Secur 80:350-371

Wang R, Zhang X, Irwin DM, Shen Y (2020d) Emergence of SARS-like coronavirus poses new challenge in China. J Inf Secur 80:350-371. https://doi.org/10.1016/j.jinf.2020.01.017

Wang Y, Zhang D, Du G et al (2020e) Remdesivir in adults with severe COVID-19: a randomised, double-blind, placebo-controlled, multicentre trial. Lancet 395:1569-1578

Wang Z, Chen X, Lu Y, et al (2020f) Clinical characteristics and therapeutic procedure for four cases with 2019 novel coronavirus pneumonia receiving combined Chinese and Western medicine treatment. Biosci Trends

Westover JB, Mathis A, Taylor R, Wandersee L, Bailey KW, Sefing EJ, Hickerson BT, Jung KH, Sheridan WP, Gowen BB (2018) Galidesivir limits Rift Valley fever virus infection and disease in Syrian golden hamsters. Antivir Res 156:38-45

Wishart DS, Knox C, Guo AC, Cheng D, Shrivastava S, Tzur D, Gautam B, Hassanali M (2008) DrugBank: a knowledgebase for drugs, drug actions and drug targets. Nucleic Acids Res 36:D901-D906

Yan R, Zhang Y, Li Y, Xia L, Guo Y, Zhou Q (2020) Structural basis for the recognition of SARS-CoV-2 by full-length human ACE2. Science 367:1444-1448. https://doi.org/10.1126/science.abb2762

Yuan M, Liu H, Wu NC, Lee CCD, Zhu X, Zhao F, Huang D, Yu W, Hua Y, Tien H, Rogers TF, Landais E, Sok D, Jardine JG, Burton DR, Wilson IA (2020) Structural basis of a shared antibody response to SARS-CoV-2. Science 369:1119-1123. https://doi.org/10.1126/ science.abd 2321

Zed PJ (2020) Pharmacy Leadership during the COVID-19 Pandemic. Can J Hosp Pharm 73:173-174

Zhang C, Wang Y, Liu X, Lu JH, Qian CW, Wan ZY, Yan XG, Zheng HY, Zhang MY, Xiong S, Li JX, Qi SY (2005) Antiviral activity of cepharanthine against severe acute respiratory syndrome coronavirus in vitro. Chin Med J 118:493-496

Zhang L, Lin D, Sun X, Curth U, Drosten C, Sauerhering L, Becker S, Rox K, Hilgenfeld R (2020) Crystal structure of SARS-CoV-2 main protease provides a basis for design of improved $\alpha$-ketoamide inhibitors. Science 368:409-412 
Zhou D, Duyvesteyn HME, Chen C-P, Huang CG, Chen TH, Shih SR, Lin YC, Cheng CY, Cheng SH, Huang YC, Lin TY, Ma C, Huo J, Carrique L, Malinauskas T, Ruza RR, Shah PNM, Tan TK, Rijal P et al (2020a) Structural basis for the neutralization of SARS-CoV-2 by an antibody from a convalescent patient. Nat Struct Mol Biol 27: 950-958. https://doi.org/10.1038/s41594-020-0480-y

Zhou N, Pan T, Zhang J, Li Q, Zhang X, Bai C, Huang F, Peng T, Zhang J, Liu C, Tao L, Zhang H (2016) Glycopeptide antibiotics potently inhibit cathepsin 1 in the late endosome/lysosome and block the entry of Ebola virus, middle east respiratory syndrome coronavirus (MERS-CoV), and severe acute respiratory syndrome coronavirus (SARS-CoV). J Biol Chem 291:9218-9232

Zhou Y, Hou Y, Shen J, Huang Y, Martin W, Cheng F (2020b) Networkbased drug repurposing for novel coronavirus 2019-nCoV/SARSCoV-2. Cell Discov 6:14. https://doi.org/10.1038/s41421-0200153-3

Zhu N, Zhang D, Wang W, Li X, Yang B, Song J, Zhao X, Huang B, Shi W, Lu R, Niu P, Zhan F, Ma X, Wang D, Xu W, Wu G, Gao GF,
Tan W, China Novel Coronavirus Investigating and Research Team (2020) A novel coronavirus from patients with pneumonia in China, 2019. N Engl J Med 382:727-733. https://doi.org/10.1056/ NEJMoa2001017

Zumla A, Chan JFW, Azhar EI, Hui DSC, Yuen KY (2016) Coronaviruses - drug discovery and therapeutic options. Nat Rev Drug Discov 15:327-347. https://doi.org/10.1038/nrd.2015.37

Zurita JL, Jos Á, del Peso A et al (2005) Ecotoxicological evaluation of the antimalarial drug chloroquine. Aquat Toxicol 75:97-107

(2020) WHO Director-General's opening remarks at the media briefing on COVID-19 - 11 March 2020. https://www.who.int/directorgeneral/speeches/detail/who-director-general-s-opening-remarks-atthe-media-briefing-on-covid-19\%2D\%2D-11-march-2020. Accessed 11 Feb 2021

Publisher's note Springer Nature remains neutral with regard to jurisdictional claims in published maps and institutional affiliations. 